\title{
Chemical and Microbiological Characterization for PDO Labelling of Typical East Piedmont (Italy) Salami
}

\author{
V. Gianotti, ${ }^{1}$ S. Panseri, ${ }^{2}$ E. Robotti, ${ }^{1}$ M. Benzi, ${ }^{1}$ E. Mazzucco, ${ }^{1}$ F. Gosetti, ${ }^{1}$ \\ P. Frascarolo, ${ }^{1}$ M. Oddone, ${ }^{1}$ M. Baldizzone, ${ }^{1}$ E. Marengo, ${ }^{1}$ and L. M. Chiesa ${ }^{2}$ \\ ${ }^{1}$ Dipartimento di Scienze dell'Ambiente e della Vita, University of Piemonte Orientale, Viale T. Michel 11, 15121 Alessandria, Italy \\ ${ }^{2}$ Dipartimento di Scienze Veterinarie e Sanita' Pubblica, University of Milano, Via Celoria 10, 20133 Milano, Italy
}

Correspondence should be addressed to V. Gianotti; gianotti@unipmn.it

Received 18 September 2014; Revised 26 December 2014; Accepted 6 January 2015

Academic Editor: Vibeke Orlien

Copyright (C) 2015 V. Gianotti et al. This is an open access article distributed under the Creative Commons Attribution License, which permits unrestricted use, distribution, and reproduction in any medium, provided the original work is properly cited.

\begin{abstract}
This study is focused on the characterisation of typical salami produced in Alessandria province (North West of Italy). Seventeen small or medium salami producers from this area were involved in the study and provided the samples investigated. The aim is double and consists in obtaining a screening of the characteristics of different products and following their evolution along ripening. The study involved five types of typical salami that were characterised for aroma components and nutritional features. This approach could provide a basis for a possible PDO or PGI label request. Principal Component Analysis and cluster analysis were used as multivariate statistical tools for data treatment. The overall results obtained point out that the products investigated do not deviate from analogous European products and show the possibility of characterising by specific parameters three main groups of samples: Salamini di Mandrogne, Muletta, and Nobile Giarolo; moreover some considerations can also be drawn with respect to the nutritional characterization considering the biogenic amines profile.
\end{abstract}

\section{Introduction}

The general term "salami" indicates stuffed meat products, very diffused and largely consumed because of their textural, sensorial, and nutritional properties. Different kinds of salami can be distinguished as a function of several factors, that is, fineness of the meat, formulation, consistency, and storage conditions [1]. The different appearance and taste also depend on the production strategies, the addition of spices, the use of microbial starters, and the environmental parameters experienced during fermentation and ripening processes. To protect the peculiarity of a typical product, it is first necessary to identify and quantify those variables that better describe its characteristics. These features permit promoting the product through the development of a certificate of origin that also reports the production process and the geographical origin. To this purpose a series of chemical and microbiological analyses are generally performed. Volatile organic compounds (VOCs) characterisation is useful to investigate the aroma properties of meat products [2-7].
The typical aroma of the products depends on a large number of volatile species, whose nature and amount can be related to the raw matter composition and the different ingredients as well as to the processing conditions including fermentation and ripening. The aroma can arise from a complex pattern of chemical reactions that take place among components, as, for example, oxidation of unsaturated fatty acids or microbiological metabolisms of lipids, proteins, and carbohydrates. The analysis of the volatile fraction has been associated with the compositional, biochemical, and microbiological characterisation to compare three Italian PDO (Protected Denomination of Origin) fermented sausages (namely, Varzi, Brianza, and Piacentino) [8]. Only few data are present regarding the characterisation of long ripened salami and, to our knowledge, no study simultaneously treats the chemical and microbiological data with methods of multivariate data analysis $[7,9]$. Characterisation analyses concerning the distinctive properties of typical products are often promoted by authorities with the aim to support the possible request of PDO and PGI (Protected Geographical 
Indication) labelling. The present paper presents a wide characterisation study of typical homemade salami produced in the Alessandria province (North West of Italy). The scope of this work regards screening the characteristics of five different products (Muletta Monferrina, Salame Nobile del Giarolo, Filetto Baciato, Tipico Tortonese, and Salamini di Mandrogne) and following their evolution along ripening: microbiological and chemical analyses were carried out regarding both nonvolatile and volatile fractions. The analysis of the nonvolatile fraction and the microbiological determinations gives information about taste, as well as about ripening time and hygienic conditions of production. In particular, the iodine value (index of the unsaturation degree of fat) $[10,11]$ and the saponification number (measure of the average molecular weight of all fat present in the sample) give useful information about the nutritional characteristics; metal content instead, in particular the rare earth elemental composition, can be very useful to provide information about the geographical provenience [12, 13]. All data collected were treated by multivariate statistical analysis techniques as Principal Component Analysis (PCA) and Cluster Analysis. PCA was firstly applied to the overall set of data collected at all the ripening stages considered, to provide a general description of the relationships existing between samples and variables. Then, the analysis was focussed on the samples collected at the selling stage only, to provide a description of the products as they reach the consumer table.

\section{Materials and Methods}

2.1. Salami Samples. Five different local salami products were involved in the study, namely, Muletta Monferrina, Salame Nobile del Giarolo, Filetto Baciato, Tipico Tortonese, Filzetta, and Salamini di Mandrogne. The samples were provided by the 17 producers cooperating to the study, in particular, nine different producers regarding Salamini di Mandrogne and two different salami factories for the other salami products. Samples were provided both at their production time $\left(T_{0}\right)$ and at different time points during ripening, comprising the selling time. Different typical products show different monitoring schedule along time, as they show different optimal ripening periods until selling: $2,3,4,5$, and 6 months $\left(T_{2}-T_{6}\right)$ for Muletta Monferrina; 1, 2, 3, and 4 months $\left(T_{1}-T_{4}\right)$ for Nobile del Giarolo; 1 and 2 months $\left(T_{1}-T_{2}\right)$ for Filetto Baciato and Tipico Tortonese. Salamini di Mandrogne were analysed only at the production time $\left(T_{0}\right)$ as they are sold fresh. The salami analysed was identified by a four-character label: the first two letters indicate the type of sample (MU = Muletta, FI = Filetto, $\mathrm{GI}=$ Giarolo, $\mathrm{SM}=$ Salamini di Mandrogne, and SA = Tipico Tortonese); the third letter indicates the manufacturer (A or $\mathrm{B})$; the fourth character is a number indicating the months of ripening and ranges from 0 (production time) to 6 (number of months of ripening). Samples were provided in triplicate by each producer for each ripening time; results for each determination were provided for each sample and the three replicates for each producer were then averaged.

2.2. Chemicals. $\mathrm{KOH} \geq 85.5 \%, \mathrm{CCl}_{4} \geq 99.8 \%, \mathrm{CH}_{3} \mathrm{COONa}$ $\geq 99 \%, \mathrm{Na}_{2} \mathrm{SO}_{4} \geq 99.5 \%, \mathrm{Na}_{2} \mathrm{HPO}_{4} \cdot 12 \mathrm{H}_{2} \mathrm{O} \geq 99 \%$, and
$\mathrm{Na}_{2} \mathrm{C}_{2} \mathrm{O}_{4} \geq 98 \%$ were purchased from Carlo Erba (Milan, Italy). $\mathrm{CuSO}_{4} \geq 99 \%, \mathrm{~K}_{2} \mathrm{SO}_{4} \geq 99 \%$, $\mathrm{Se} \geq 99 \%, \mathrm{H}_{2} \mathrm{SO}_{4} \geq 95-$ $98 \%, \mathrm{NaOH} \geq 98 \%, \mathrm{KI} \geq 99 \%, \mathrm{HCOOH} \geq 96 \%$ ACS, $\mathrm{KNO}_{2} \geq$ $97 \%, \mathrm{CH}_{3} \mathrm{COONH}_{4} \geq 99.9 \%, \mathrm{Na}_{2} \mathrm{~S}_{2} \mathrm{O}_{3} \geq 99 \%, 1 \%(\mathrm{w} / \mathrm{V})$ water solution of starch indicator, L-lysine $\geq 98 \%$, tryptamine hydrochloride 99\%, methyl red crystals ACS reagent, phenolphthalein RPE-ACS, and the C6-C22 series of $n$-alkanes were purchased from Sigma-Aldrich (Schnelldorf, Germany). Acetonitrile $\geq 99.9 \%$ HPLC grade, $\mathrm{HCOONH}_{4} \geq 99.9 \%$, and $\mathrm{HCl} \geq 37 \%$ were purchased from VWR International (Darmstadt, Germany). Ethyl alcohol $\geq 99.8 \%$, cadaverine dihydrochloride $>99 \%$, histamine dihydrochloride $>99 \%$, dansyl chloride $\geq 99 \%$, petroleum ether puriss. p.a. ACS reagent bp $40-60^{\circ} \mathrm{C}$, L-histidine $\geq 99.5 \%$, L-tyrosine $\geq 99 \%$, octylamine $\geq 99 \%, \mathrm{NaHCO}_{3} \geq 99 \%$, and $\mathrm{HNO}_{3} \geq 69.5 \%$ were purchased from Fluka (Buchs, Switzerland). $\mathrm{H}_{3} \mathrm{PO}_{4} \geq 85 \%$, $\mathrm{KNO}_{3} \geq 99 \%, \mathrm{KCl} \geq 99.5 \%$, and Symphony potentiometric buffer solutions ( $\mathrm{pH} 4.00,7.00$, and 10.00) were purchased from Merck (Darmstadt, Germany). Hydromatrix was purchased from Varian (Palo Alto, CA, USA) and Wijs solution $0.1 \mathrm{M}$ in acetic acid from Riedel de Haen (Seelze, Germany). MRS agar was purchased from LAB M (Bury, UK), Tryptone Soya Agar and Mannitol Salt Agar were purchased from Oxoid (Rodano Milan, Italy). Ultrapure water was produced by a Millipore Milli-Q system (Milford, MA, USA).

2.3. Equipment. The following apparatus were used for the preparation of the samples: Stomacher Circulator (PBI International, Milan, Italy), oven EWTQ905 (Falc Instruments, Treviglio, Bergamo, Italy), muffle Pyro High Temperature Microwave (Milestone, Shelton, CT, USA), accelerated solvent extractor ASE 100 (Dionex, Sunnyvale, CA), centrifuge IC CL31R Multispeed (Thermo Electron Corporation, Waltham, MA, USA), and Sartorius balance CP225D-0CE (0.00001 g) (Goettingen, Germany). pH measurements were performed by a Symphony SB70P pH meter (VWR, Darmstadt, Germany), equipped with a combined glass $\mathrm{Ag} / \mathrm{AgCl}$ electrode. Conductivity was measured by a conductometer ATC HI 9033 (Hanna Instruments, Woonsocket, RI, USA). HPLC analyses of nitrite and nitrate ions were carried out by a Merck-Hitachi HPLC system (Tokyo, Japan) equipped with L-6200 intelligent pump interfaced to an L-4250 UVVis detector and to D-2500 Chromato-integrator. Biogenic amines and their precursor amino acids were determined by HPLC Spectra System (Providence, RI, USA), equipped with a Spectra System pump P4000, a Spectra System SCM 1000 degasser, an autosampler Spectra System AS 3000, UV 6000 LP detector, and the software ChromQuest. Metals determination was performed by a Thermo Fisher XSeries 2 ICP-MS (Winsford, UK), equipped with an Apex-Q fullyintegrated inlet system (Elemental Scientific Inc. Omaha, USA) and the software PlasmaLab V2.5.4.289. The analysis of volatile compounds was carried out on a TraceGC Ultra gas chromatograph (Thermo Finnigan, Milan, Italy) equipped with a split/splitless (SSL) injector, a CombiPal (CTC analytics, Zwingen, Switzerland) autosampler and coupled with a TRACE DSQ (Finnigan, Milan, Italy) mass spectrometer. 
2.4. Sample Pretreatment. The salami samples delivered to our laboratory were immediately sliced and minced. In a portion of the fresh sample, treated as successively described, $\mathrm{pH}$, moisture, conductivity, nitrite, and nitrate content were immediately determined, while all other analyses were performed on the fraction stored in freezer at $-25^{\circ} \mathrm{C}$. To measure $\mathrm{pH}$, conductivity, nitrite, and nitrate, $10.0 \mathrm{~g}$ of fresh sample was kept in contact with $90.0 \mathrm{~mL}$ of ultrapure water in a stomacher bag and digested for $5.0 \mathrm{~min}$ at $270 \mathrm{rpm}$; then the extract was filtered on filter paper. For the determination of fat and iodine value, a sample of $10.0 \mathrm{~g}$ of thawed salami was put in an ASE (Accelerated Solvent Extraction) cell with $5.0 \mathrm{~g}$ of hydromatrix and extracted by petroleum ether performing 3 cycles of extraction of $10.0 \mathrm{~min}$ each, at $160.0^{\circ} \mathrm{C}$.

For ash percentage and metal ion determinations, $5.0 \mathrm{~g}$ of sample was treated in muffle under a linear temperature gradient reaching $820.0^{\circ} \mathrm{C}$ in $1 \mathrm{~h} 20^{\prime}$. The analysis of volatile compounds was performed on $10.0 \mathrm{~g}$ of sample cut in very thin slices and weighted into a $20.0 \mathrm{~mL}$ headspace vial, sealed with polytetrafluoroethylene- (PTFE-) coated silicone rubber septum (20 mm diameter), where they were left for $60 \mathrm{~min}$ at $25^{\circ} \mathrm{C}$. After each analysis the fibre was kept for $15 \mathrm{~min}$ at $280^{\circ} \mathrm{C}$.

\subsection{Methods}

2.5.1. HPLC Determination of Nitrite and Nitrate. Nitrite and nitrate determination was performed on the stomacher aqueous extract filtered on a $0.22 \mu \mathrm{m}$ PTFE filter (VWR International, Darmstadt, Germany) and diluted 1/10 v/v.

The mobile phase was an aqueous solution of octylamine $5.0 \mathrm{mM}$ brought to $\mathrm{pH} 6.4$ by o-phosphoric acid; the stationary phase was a Lichrospher C18e $(250 \times 4 \mathrm{~mm}$, $5 \mu \mathrm{m})$ column with a Lichrospher RP-18 $(5 \mu \mathrm{m})$ precolumn (Merck, Darmstadt, Germany). The mobile phase flow rate was $1.0 \mathrm{~mL} \mathrm{~min}^{-1}$, the injection volume was $100.0 \mu \mathrm{L}$, and wavelength of the UV detector was set at $205 \mathrm{~nm}$.

\subsubsection{HPLC Determination of Amino Acids and Biogenic} Amines. The dansylation reaction of aminoacids and biogenic amines was performed on a solution obtained putting $10.0 \mathrm{~g}$ of sample in contact with $100.0 \mathrm{~mL} \mathrm{HCl} 0.1 \mathrm{M}$ in a stomacher bag and digested for $5.0 \mathrm{~min}$ at $270 \mathrm{rpm}$; the extract was centrifuged for $10.0 \mathrm{~min}$ at $8000 \mathrm{rpm}(25000 \times \mathrm{g})$. $1200 \mu \mathrm{L}$ of extract was put in contact with $1200 \mu \mathrm{L}$ of $\mathrm{NaHCO}_{3}$ and $1200 \mu \mathrm{L}$ of a dansyl chloride solution $0.02 \mathrm{M}$ in acetone. The mixture was kept at dark for $40.0 \mathrm{~min}$ at $65^{\circ} \mathrm{C}$ and then centrifuged for $2.0 \mathrm{~min}$ at $10000 \mathrm{rpm}$ and undergone to solid phase extraction (SPE). After conditioning the C18 SPE cartridge (50 mg of sorbent) (Phenomenex, Bologna, Italy) with $2.00 \mathrm{~mL}$ of methanol and $2.00 \mathrm{~mL}$ of a water/acetone $50 / 50(\mathrm{v} / \mathrm{v})$ mixture, $2.00 \mathrm{~mL}$ of the derivatized sample was loaded and a washing step was performed with $3.00 \mathrm{~mL}$ of Milli Q water. The cartridge was dried under nitrogen and the sample recovered in $2.00 \mathrm{~mL}$ of methanol. For the HPLC determination of biogenic amines and precursor aminoacids, a Lichrospher C18e $(250 \times 4 \mathrm{~mm}, 5 \mu \mathrm{m})$ column with a Lichrospher RP-18 $(5 \mu \mathrm{m})$ precolumn (Merck, Darmstadt, Germany) was employed, while the mobile phase was a mixture of $\mathrm{CH}_{3} \mathrm{COONH}_{4} 9.0 \mathrm{mM}$ (at $\mathrm{pH} 3.40$ for $\mathrm{HCOOH}$ ) (41\%) and acetonitrile (59\%). The mobile phase flow rate was $1.0 \mathrm{~mL} \mathrm{~min}^{-1}$ and the UV detector set at $254 \mathrm{~nm}$.

2.5.3. Water Content. Water content was determined by the comparison of the solid sample weights before $(5.0 \mathrm{~g})$ and after the oven treatment performed at $105.0^{\circ} \mathrm{C}$ for $2.5 \mathrm{~h}$ [15].

2.5.4. Saponification Value. The saponification value $(S)$ was determined directly on $5.0 \mathrm{~g}$ of salami put in contact with $25.00 \mathrm{~mL}$ of $0.5 \mathrm{~N}$ ethanol solution of $\mathrm{KOH}$ in a flask equipped with a reflux condenser. The system was heated for $20 \mathrm{~min}$ and then the mixture was centrifuged for $5 \mathrm{~min}$ at $5000 \mathrm{rpm}$; the supernatant was titrated with $\mathrm{HCl} 0.5 \mathrm{~N}$, phenolphthalein being the indicator.

The saponification value was calculated through the following equation:

$$
S=\frac{\left(V_{b}-V_{s}\right) \cdot 28.05}{w},
$$

where $V_{b}$ is the volume $(\mathrm{mL})$ of titrant used in the blank titration, $V_{s}$ is the volume $(\mathrm{mL})$ obtained in the titration of the sample, and $w$ is the weight (5.0 g) of the sample.

2.5.5. Fat Content. The fat content was determined by weighting the residual of the ASE extract after complete solvent evaporation [16].

2.5.6. Iodine Value. The iodine value (I) was determined by adding $20.00 \mathrm{~mL}$ of $\mathrm{CCl}_{4}$ to the ASE extract. After agitation for $5 \mathrm{~min}, 25.00 \mathrm{~mL}$ of Wijs solution was added and the resulting mixture was kept at dark for $1 \mathrm{~h}$; after addition of $20.00 \mathrm{~mL}$ of KI solution $10 \% \mathrm{w} / \mathrm{v}$, the solution was titrated with $\mathrm{Na}_{2} \mathrm{~S}_{2} \mathrm{O}_{3} 0.1 \mathrm{~N}$ with starch solution as indicator. The iodine value is calculated as follows:

$$
I=\frac{\left(V_{b}-V_{s}\right) \cdot 12.69}{w},
$$

where $V_{b}$ is the volume $(\mathrm{mL})$ employed in the titration of the blank, $V_{s}$ is the volume $(\mathrm{mL})$ employed in the titration of the sample, and $w$ is the weight (g) of sample [17].

2.5.7. Ash Content. The ash content was determined by weighting the muffle mineralised sample after $20 \mathrm{~min}$ of cooling at room temperature.

2.5.8. Protein Determination according to the Kjeldahl Method. $1.0 \mathrm{~g}$ of the sample was placed in Kjeldahl flask and added with $20.0 \mathrm{~g}$ of $\mathrm{K}_{2} \mathrm{SO}_{4}, 0.55 \mathrm{~g}$ of $\mathrm{CuSO}_{4}, 0.75 \mathrm{~g}$ of Se, and $35.0 \mathrm{~mL}$ of $\mathrm{H}_{2} \mathrm{SO}_{4} 18 \mathrm{M}$. The flask was heated in a mantle for one hour at the solution fuming temperature. Then $100.0 \mathrm{~mL}$ of ultrapure water and $250.0 \mathrm{~mL}$ of $\mathrm{NaOH} 20 \%(\mathrm{w} / \mathrm{v})$ were added to the cooled solution and the resulting mixture was heated. The first $50 \mathrm{~mL}$ of the distilled fraction was recovered in a flask, containing $50.0 \mathrm{~mL}$ of $\mathrm{HCl} 0.1 \mathrm{~N}$. The excess of $\mathrm{HCl}$ was 
titrated with $\mathrm{NaOH} 0.1 \mathrm{~N}$, methyl red as the indicator. The \% of nitrogen $(\% \mathrm{~N})$ was calculated as

$$
\% \mathrm{~N}=\frac{\mathrm{eq}_{\mathrm{H}^{+}} \cdot 14.008}{w} \cdot 100
$$

where $\mathrm{eq}_{\mathrm{H}^{+}}$are the equivalents of $\mathrm{H}^{+}$consumed by the distilled basic fraction and $w$ is the weight (g) of the sample. Protein content was estimated by multiplying the Kjeldahl nitrogen content by 6.25 [18].

2.5.9. Determination of Volatile Compounds. The analysis of volatile compounds was performed on $10.00 \mathrm{~g}$ of sample cut in very thin slices and weighted into a $20.00 \mathrm{~mL}$ headspace vial, sealed with polytetrafluoroethylene- (PTFE-) coated silicone rubber septum (20 $\mathrm{mm}$ diameter), added with $1.00 \mathrm{~mL}$ of the internal standard 4-methyl-2-pentanone aqueous solution at the concentration of $2.00 \mathrm{~g} \mathrm{~mL}^{-1}$. They were left for $60 \mathrm{~min}$ at $25^{\circ} \mathrm{C}$. Headspace was extracted by SPME technique using a CAR/PDMS fibre, $75 \mu \mathrm{m}$ film thickness (Supelco, Bellefonte, PA, USA). Fibres exposition time of $90 \mathrm{~min}$ at $25^{\circ} \mathrm{C}$ was adopted [19]. The fibre was then introduced into the injector of a gas chromatograph at $220^{\circ} \mathrm{C}$ and the sample injected by splitless mode for 8 minutes. The source and transfer line temperatures were set at $250^{\circ} \mathrm{C}$ and $230^{\circ} \mathrm{C}$, respectively. After each analysis the fibre was kept for $15 \mathrm{~min}$ at $280^{\circ} \mathrm{C}$. The GC system was equipped with a fused-silica capillary column (Rtx-WAX, $30 \mathrm{~m} \times 0.25 \mathrm{~mm}$ i.d., film thickness $0.25 \mu \mathrm{m}$ ). Helium was used as carrier gas at

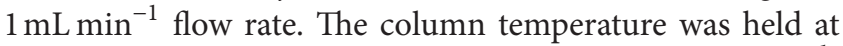
$35^{\circ} \mathrm{C}$ for $8 \mathrm{~min}$, increased from $35^{\circ} \mathrm{C}$ to $60^{\circ} \mathrm{C}$ at $4^{\circ} \mathrm{C} \mathrm{min}{ }^{-1}$, from $60^{\circ} \mathrm{C}$ to $160^{\circ} \mathrm{C}$ at $6^{\circ} \mathrm{C} \mathrm{min}^{-1}$, and from $160^{\circ} \mathrm{C}$ to $200^{\circ} \mathrm{C}$

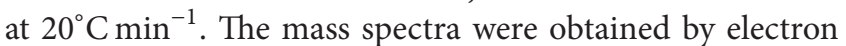
impact at $70 \mathrm{eV}$ with the detector operating in scan mode (total ion current) from $m / z 35$ to 350 a.m.u., with scanning velocity of $2.48 \mathrm{scan} \mathrm{s}^{-1}$. The identification of volatile compounds was carried out by comparing GC retention time and MS spectra with those of standard compounds. Nist 98 and Wiley 275 mass spectral libraries were used when standard compounds were unavailable. A series of $n$-alkanes (C6-C22) was also determined under the same conditions to obtain linear retention index (LRI) values for the aroma components. Quantitative analyses of samples were carried out by using the internal standard procedure and expressed as ng IS equivalents.

2.5.10. Microbiological Analysis. The microbiological analyses were performed on $10.0 \mathrm{~g}$ of sample. Lactic acid bacteria (lactobacillus) counts were determined by the overlay technique using MRS agar and colonies counted after incubation in anaerobic conditions after $72 \mathrm{~h}$ at $30^{\circ} \mathrm{C}$; total count was performed on Tryptone Soya Agar after $72 \mathrm{~h}$ at $30^{\circ} \mathrm{C}$; Micrococcaceae were determined on Mannitol Salt Agar after $24 \mathrm{~h}$ at $42^{\circ} \mathrm{C}$. All bacteria counts were expressed as colony forming per gram of sample $\left(\mathrm{CFU} \mathrm{g}^{-1}\right)$.

2.6. Statistical Analysis. All statistical treatments, Principal Component Analysis (PCA), and graphical representations were carried out by Statistica version 7.1 (StatSoft Inc, USA) and Microsoft Excel (Microsoft Corporation, USA).

\section{Results and Discussion}

3.1. Physical-Chemical and Nonvolatile Fraction Analyses. While PDO protocols are already available for other Italian Salami, as Varzi, Brianza, and Piacentino salami [8] and UNI standard values are reported for Felino or Milano $[6,15,16]$, this is not yet the case for the salami here considered. Taking into account that the samples investigated are produced at homemade level, in order to identify parameters suitable for the definition of PDO and PGI, a high number of variables have been evaluated. As reported above, the products considered are characterised by different ripening procedures: Salamini di Mandrogne are sold without ripening, Muletta after a six-month ripening period, and Filetto Baciato, Nobile del Giarolo, and Tipico Tortonese after ripening times that vary between two and three months. The analyses were performed at regular time intervals (one month) during the ripening period, ranging from the production time to the selling time for all products except for Salamini di Mandrogne, for which the analyses were performed only at the productioncommercialisation time. Some considerations and comparison can be made among the data reported in Tables 1 and 2 .

Water percentage (Table 1) varies from about $56 \%$ at the production time for Salamini di Mandrogne to about $20 \%$ at the end of ripening of Nobile del Giarolo samples. Weight loss during ripening varies from about $29 \%$ of MUA samples to about $7 \%$ of SAA samples: different variations can be ascribed to the ripening conditions, performed in a traditional cellar for Muletta and Nobile del Giarolo samples and in industrial climatic chambers for the other products. $\mathrm{pH}$ values at the production time are all lower than 6.0 and, in agreement with data found for other meat products [8] trend to increase during ripening. Likely due to an intense deaminase oxidative activity, induced in particular by moulds [8], $\mathrm{pH}$ values increase during ripening for $M U A$ and $G I B$ and in particular for GIA sample, probably due to the traditional room in which this product is ripened [9]. Table 1 also shows that the content of fat and proteins is similar, at the end of ripening, for nearly all samples, in agreement with literature data for typical north Italian salami $[8,9,13]$, with the only exception of Filetto Baciato and Salamini di Mandrogne. The lower fat content for Filetto can be explained taking into account that this product is constituted by a central lean fillet of pork surrounded by a salami mixture. The iodine value largely varies within the different samples. The values at the selling time are generally lower than literature data for European salami [20] that, in turn, are lower than values obtained for products from other countries. Saponification number, providing a measure of chain length of fatty acids, ranges from 78 to $179 \mathrm{mg} \mathrm{KOH} \mathrm{g}^{-1}$ and is consistent with average values for meat products [11]. Nitrite and nitrate contents (Table 1) must be compared with Italian law threshold concentration levels, reported in the D.M. 27/02/1996 n. 209, that considers two different levels. One indicates the maximum amount that can be added $\left(150 \mathrm{mg} \mathrm{Kg}^{-1}\right.$ for sodium nitrite and $300 \mathrm{mg} \mathrm{Kg}^{-1}$ for sodium nitrate) while the other gives 


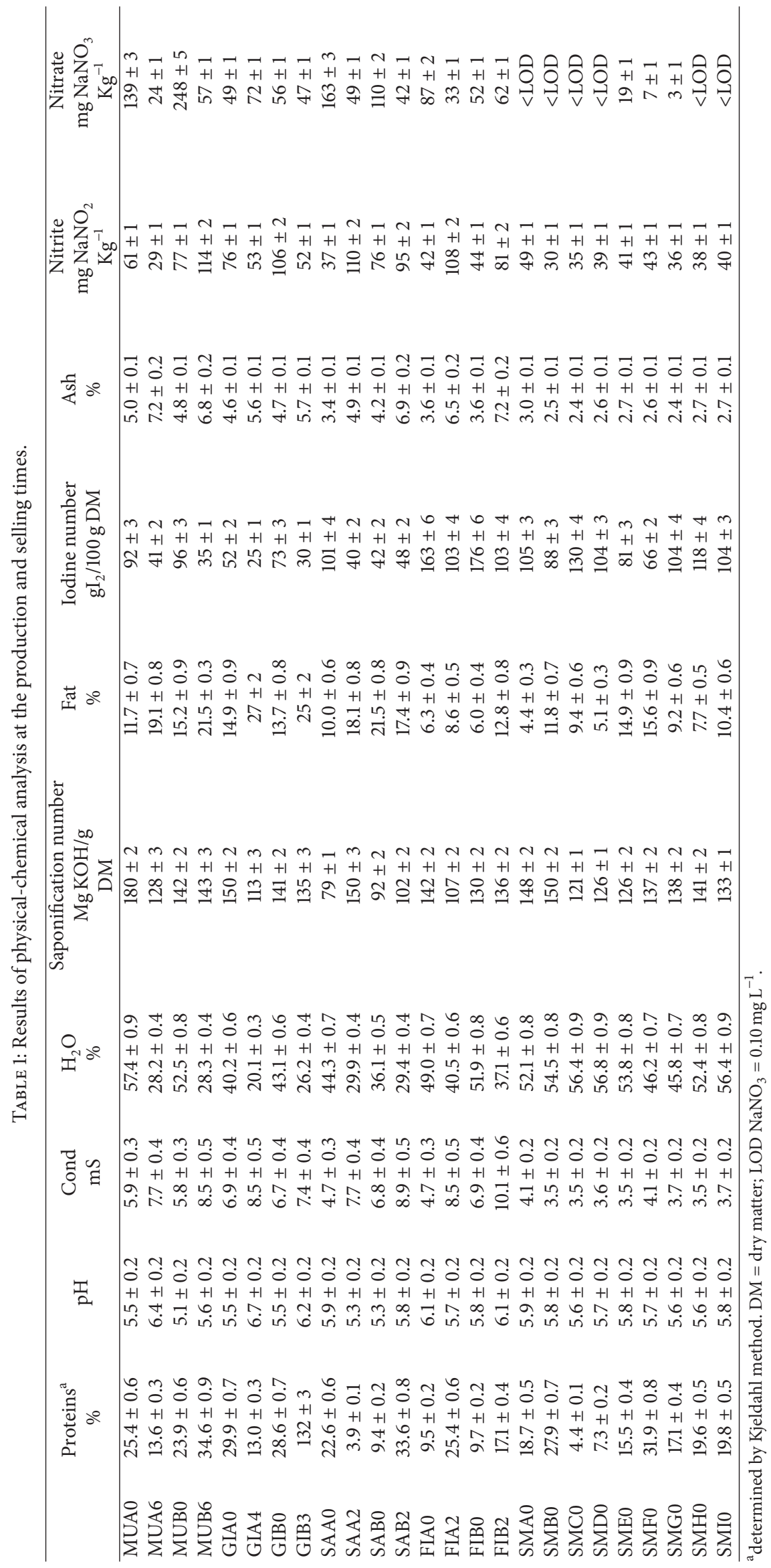


TABLE 2: Results of biogenic amines and precursor amino acids determination for the production and selling times.

\begin{tabular}{|c|c|c|c|c|c|c|c|c|}
\hline & $\begin{array}{c}\text { LYS } \\
\mathrm{mg} \mathrm{Kg}^{-1} \\
\mathrm{DM}\end{array}$ & $\begin{array}{c}\text { HISTID } \\
\mathrm{mg} \mathrm{Kg}^{-1} \\
\text { DM }\end{array}$ & $\begin{array}{c}\text { TRYPT } \\
\mathrm{mg} \mathrm{Kg}^{-1} \\
\text { DM }\end{array}$ & $\begin{array}{c}\text { TYROS } \\
\mathrm{mg} \mathrm{Kg}^{-1} \\
\text { DM }\end{array}$ & $\begin{array}{c}\mathrm{CAD} \\
\mathrm{mg} \mathrm{Kg}^{-1} \\
\mathrm{DM}\end{array}$ & $\begin{array}{c}\text { HIS } \\
\mathrm{mg} \mathrm{Kg}^{-1} \\
\text { DM }\end{array}$ & $\begin{array}{c}\text { TYR } \\
\mathrm{mg} \mathrm{Kg}^{-1} \\
\mathrm{DM}\end{array}$ & $\begin{array}{c}\text { Total ABS } \\
\mathrm{mg} \mathrm{Kg}^{-1} \\
\text { DM }\end{array}$ \\
\hline MUA0 & $<$ LOD & $460 \pm 14$ & $62 \pm 2$ & $<\mathrm{LOD}$ & $94 \pm 3$ & $375 \pm 12$ & $304 \pm 9$ & 835 \\
\hline MUA6 & $269 \pm 8$ & $112 \pm 3$ & $68 \pm 2$ & $<\mathrm{LOD}$ & $204 \pm 6$ & $406 \pm 13$ & $192 \pm 6$ & 870 \\
\hline MUB0 & $506 \pm 15$ & $351 \pm 10$ & $<\mathrm{LOD}$ & $<\mathrm{LOD}$ & $<\mathrm{LOD}$ & $<\mathrm{LOD}$ & $146 \pm 4$ & 146 \\
\hline MUB6 & $1103 \pm 34$ & $888 \pm 26$ & $<\mathrm{LOD}$ & $<\mathrm{LOD}$ & $30 \pm 1$ & $208 \pm 7$ & $280 \pm 9$ & 519 \\
\hline GIA0 & $485 \pm 15$ & $207 \pm 6$ & $<\mathrm{LOD}$ & $<\mathrm{LOD}$ & $59 \pm 2$ & $236 \pm 7$ & $128 \pm 4$ & 423 \\
\hline GIA4 & $649 \pm 20$ & $213 \pm 6$ & $35 \pm 1$ & $<\mathrm{LOD}$ & $72 \pm 2$ & $244 \pm 8$ & $113 \pm 3$ & 465 \\
\hline GIB0 & $511 \pm 15$ & $437 \pm 13$ & $45 \pm 1$ & $198 \pm 4$ & $<\mathrm{LOD}$ & $<\mathrm{LOD}$ & $119 \pm 4$ & 410 \\
\hline GIB3 & $<\mathrm{LOD}$ & $418 \pm 12$ & $38 \pm 1$ & $<\mathrm{LOD}$ & $<\mathrm{LOD}$ & $246 \pm 8$ & $95 \pm 3$ & 133 \\
\hline SAA0 & $129 \pm 3$ & $127 \pm 4$ & $<\mathrm{LOD}$ & $<\mathrm{LOD}$ & $<\mathrm{LOD}$ & $252 \pm 8$ & $<\mathrm{LOD}$ & 252 \\
\hline SAA2 & $1602 \pm 49$ & $397 \pm 12$ & $51 \pm 1$ & $<\mathrm{LOD}$ & $<\mathrm{LOD}$ & $257 \pm 8$ & $134 \pm 4$ & 443 \\
\hline SAB0 & $431 \pm 13$ & $313 \pm 9$ & $<\mathrm{LOD}$ & $179 \pm 4$ & $<\mathrm{LOD}$ & $<\mathrm{LOD}$ & $<\mathrm{LOD}$ & - \\
\hline SAB2 & $<\mathrm{LOD}$ & $662 \pm 20$ & $44 \pm 1$ & $273 \pm 6$ & $<\mathrm{LOD}$ & $216 \pm 7$ & $159 \pm 5$ & - \\
\hline FIA0 & $130 \pm 4$ & $147 \pm 4$ & $33 \pm 1$ & $<\mathrm{LOD}$ & $<\mathrm{LOD}$ & $<\mathrm{LOQ}$ & $43 \pm 1$ & 273 \\
\hline FIA2 & $595 \pm 18$ & $322 \pm 10$ & $43 \pm 1$ & $<\mathrm{LOD}$ & $<\mathrm{LOD}$ & $197 \pm 6$ & $118 \pm 4$ & 160 \\
\hline FIB0 & $139 \pm 4$ & $158 \pm 5$ & $33 \pm 1$ & $<\mathrm{LOD}$ & $<\mathrm{LOD}$ & $290 \pm 9$ & $<\mathrm{LOD}$ & 323 \\
\hline FIB2 & $341 \pm 10$ & $131 \pm 4$ & $43 \pm 1$ & $<\mathrm{LOD}$ & $35 \pm 1$ & $214 \pm 7$ & $112 \pm 3$ & 405 \\
\hline SMA0 & $138 \pm 4$ & $149 \pm 4$ & $<$ LOD & $<\mathrm{LOD}$ & $<\mathrm{LOD}$ & $<\mathrm{LOD}$ & $<\mathrm{LOD}$ & - \\
\hline SMB0 & $<\mathrm{LOD}$ & $173 \pm 5$ & $<\mathrm{LOD}$ & $<\mathrm{LOD}$ & $<\mathrm{LOD}$ & $<\mathrm{LOD}$ & $<\mathrm{LOD}$ & - \\
\hline SMC0 & $139 \pm 4$ & $229 \pm 7$ & $<\mathrm{LOD}$ & $<\mathrm{LOD}$ & $<\mathrm{LOD}$ & $311 \pm 10$ & $<\mathrm{LOD}$ & 311 \\
\hline SMD0 & $175 \pm 5$ & $178 \pm 5$ & $<\mathrm{LOD}$ & $<\mathrm{LOD}$ & $<\mathrm{LOD}$ & $328 \pm 11$ & $<\mathrm{LOD}$ & 328 \\
\hline SME0 & $180 \pm 5$ & $181 \pm 5$ & $<$ LOD & $<\mathrm{LOD}$ & $<\mathrm{LOD}$ & $<\mathrm{LOD}$ & $<\mathrm{LOD}$ & - \\
\hline SMF0 & $109 \pm 4$ & $141 \pm 4$ & $<\mathrm{LOD}$ & $<\mathrm{LOD}$ & $<\mathrm{LOD}$ & $257 \pm 8$ & $<\mathrm{LOD}$ & 258 \\
\hline SMG0 & $61 \pm 2$ & $126 \pm 3$ & $<\mathrm{LOD}$ & $<\mathrm{LOD}$ & $<\mathrm{LOD}$ & $<\mathrm{LOD}$ & $<\mathrm{LOD}$ & - \\
\hline SMH0 & $90 \pm 2$ & $146 \pm 4$ & $<\mathrm{LOD}$ & $<\mathrm{LOD}$ & $<\mathrm{LOD}$ & $<\mathrm{LOD}$ & $<\mathrm{LOD}$ & - \\
\hline SMI0 & $124 \pm 4$ & $210 \pm 6$ & $<$ LOD & $<\mathrm{LOD}$ & $<\mathrm{LOD}$ & $313 \pm 10$ & $<\mathrm{LOD}$ & 313 \\
\hline
\end{tabular}

$\mathrm{DM}=$ dry matter; LOD lysine $=40 \mu \mathrm{g} \mathrm{L}-1$, cadaverine $=52 \mu \mathrm{g} \mathrm{L}^{-1}$, histamine $=104 \mu \mathrm{g} \mathrm{L}-1$, histidine $=159 \mu \mathrm{g} \mathrm{L}^{-1}$, tyramine $=62 \mu \mathrm{g} \mathrm{L} \mathrm{L}^{-1}$, and tryptamine $=$ $45 \mu \mathrm{g} \mathrm{L}^{-1}$.

the maximum residual content that can be present at the selling time and corresponds to $50 \mathrm{mg} \mathrm{Kg}^{-1}$ for sodium nitrite and to $250 \mathrm{mg} \mathrm{Kg}^{-1}$ for sodium nitrate. Regarding nitrite, its amount is always larger than $29 \mathrm{mg} \mathrm{Kg}^{-1}$ and for five samples (namely, MUB6, SAA2, SAB2, FIA2, and FIB2) they are above the law limit at the selling time: this is a quite common situation since nitrite slowly transforms into nitrate during ripening and these products are not supposed to be consumed fresh. Table 2 reports the amounts, corrected for moisture, obtained for cadaverine (CAD), histamine (HIS), histidine (HISTID), tyramine (TYR), tryptamine (TRYP), tyrosine (TYROS), and lysine (LYS). Both the total amount of BAs and the HIS/HISTID concentration ratio increase during ripening. At the selling time, tyramine is present in all samples at concentrations ranging from 95 to $280 \mathrm{mg} \mathrm{Kg}^{-1}$. Anyway the total BAs amount is always lower than the level (1000 $\mathrm{mg} \mathrm{Kg}^{-1}$ ) reported as dangerous for human health [21], where $870 \mathrm{mg} \mathrm{Kg}^{-1}$ is the maximum amount obtained at the selling time. However, a univocal toxic level is difficult to define since individual sensitivity can be very different and can also be related to the specific biogenic amine considered.
Regarding the content of BAs in fresh products (production time), the samples generally show content unexpectedly high of histamine and tyramine $[1,22]$.

Salamini di Mandrogne do not contain tyramine, cadaverine, and tryptamine but the samples $S M C, S M D, S M F$, and SMI show concentrations of histamine of about $300 \mathrm{mg} \mathrm{Kg}^{-1}$.

3.2. Microbiological Analyses. The results of microbiological analyses are presented in Figures 1 and 2, in which lactic acid bacteria and Micrococcaceae are reported as a function of ripening time. The results showed that the raw mixtures $\left(T_{0}\right)$ were characterised by good hygienic conditions and suitable presence of lactic acid bacteria and Micrococcaceae that assists a correct fermentation process.

The microbiological trend is similar for all products. The counts of acid lactic bacteria and Micrococcaceae generally showed a maximum at one month of ripening $\left(T_{1}\right)$ for all the samples and then decreased until the end of ripening. The only exception is represented by Muletta that showed the highest counts of lactic acid bacteria and Micrococcaceae at $T_{2}$, probably due to its large size, that can affect 


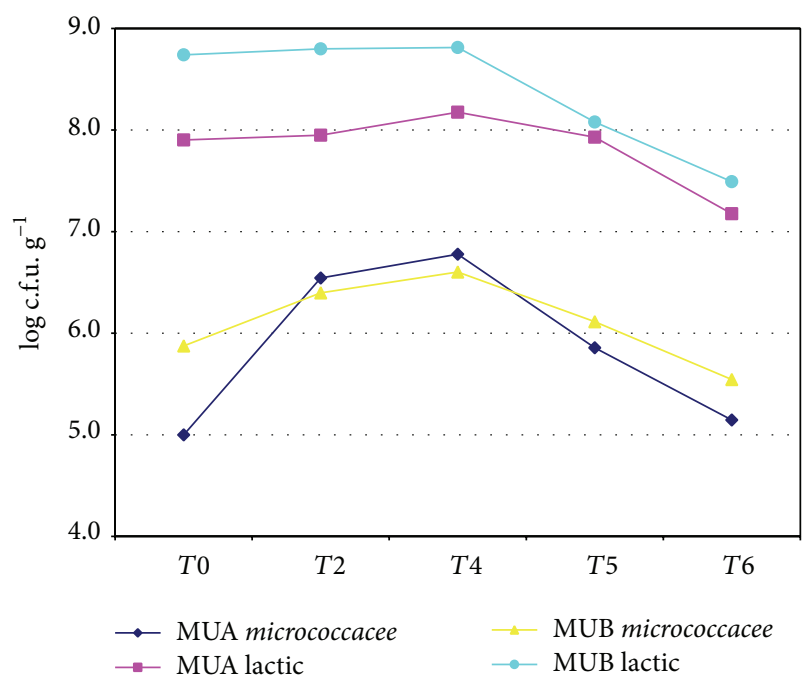

Figure 1: Evolution of Micrococcaceae and lactic acid bacteria during ripening of Muletta salami (log c.f.u. $\left.\mathrm{g}^{-1}\right)$.

the growth of lactobacilli and Micrococcaceae. Also the amount of volatile compounds showed a similar trend, likely due to the formation of metabolites (e.g., esters, alcohols, and ketones) produced during the fermentation process. Salamini of Mandrogne (fresh sausages) showed a mean value of $8 *$ $10^{6}$ u.f.c. $g^{-1}$ for acid lactic bacteria.

3.3. Volatile Compounds Analysis. About 70 volatile substances including terpenes, esters, ketones, alcohols, aldehydes, and sulphur compounds were searched and determined in all samples (Tables 3, 4, 5, and 6).

The compounds were identified using both chromatographic (Kovats indices) and spectrometric (mass spectra, EI, $70 \mathrm{eV}$ ) criteria. Kovats indices were calculated for each chromatographic peak and compared with those stored in a proprietary database including about 250 volatile compounds usually found in food matrices $[9,14,23,24]$. Determination of the volatile constituents was carried out by spiking the salami, before the extraction, with 4-methyl-2-pentanone $\left(2.0 \mu \mathrm{g} \mathrm{mL}^{-1}\right)$, used as the internal standard since preliminary results indicated its absence in all the samples. The lowest content of volatile species was found in Filetto Baciato: the result is likely due to its composition, constituted by a central lean fillet of pork inside the salami texture. In all products the largest group of volatiles was represented by terpenes, where $\alpha$-pinene, $\beta$-pinene, sabinene, limonene, and $\beta$-caryophyllene are the most abundant. Terpenes can derive from animal feedstuffs and mainly from the spices as black pepper, nutmeg, and clove added during production. In particular nutmeg contains $\alpha$-pinene, $\beta$-pinene, sabinene, and limonene and clove $\beta$-caryophyllene $[7,25]$. The maximum terpene compounds concentration was observed at the end of the ripening period in Nobile del Giarolo and Filetto Baciato, while in Muletta it was reached at about 4 months of ripening $\left(T_{4}\right)[26,27]$. Four sulphur containing compounds were identified and quantified in Filetto Baciato and Nobile del Giarolo and six compounds in Muletta, the most abundant being allyl methyl sulphide. Sulphur compounds mainly derive from garlic and represent important aroma compounds, since they are characterised by very low sensory thresholds [28]. The amounts of sulphur containing species increased during the ripening, except for Muletta that showed a decreasing trend after the $T_{4}$ of ripening. Many ketones and alcohols were found to be present. The most abundant ketones were 2-butanone, 3-hydroxy-2-butanone (acetoin), and 2-propanone; their concentrations increased reaching a maximum at the end of ripening except in Muletta where the amount increases until $T_{5}$ and then decreases.

The most abundant alcohols isolated were ethanol, 2butanol, 3-methyl-1-butanol, 1-propanol, and 1-octen-3-ol, which in particular is produced during lipid oxidation and is recognised for a characteristic mushroom note and a very low sensory threshold [4].

High amounts of ethanol were found in all products, likely arising from the wine added during preparation. Also 3-methyl-1-butanol was found in all the products, likely formed through the reduction reaction of the corresponding aldehyde $[3,19,29]$.

Several ethyl esters were isolated in particular in Muletta. Since esters can be formed in a complex chain of reactions such as alcohol-aldehyde-acid-ester, ethyl esters are usually present in fermented meat products and contribute to the fruity note of the flavour $[6,20,30,31]$. The long ripening time undergone by Muletta likely favoured therefore their formation. Aldehydes were identified and quantified in Filetto Baciato, Muletta, and Nobile del Giarolo. The total aldehyde content increased during ripening, especially in Filetto Baciato and Nobile del Giarolo, while showing a maximum at $T_{4}$ for Muletta. Many aldehydes are products of lipid oxidation. In particular hexanal, which is produced during the oxidation of n-6 unsaturated fatty acids, imparts a green odour and is considered a good indicator of oxidation [30]. The low amount of hexanal found in all the salami could likely be attributed to the antioxidative activity of terpenes of spices found at higher concentration levels in all the products. All the products contain benzenacetaldehyde that is considered one of the substances giving a specific flavour note to pork meat and can form from phenylalanine. Among free fatty acids the most abundant compounds identified in all the salami were acetic acid, butanoic acid, 2-methyl propanoic acid, and 3-methyl butanoic acid. The total amount of fatty acids increased during the ripening in Nobile del Giarolo and Filetto Baciato, while reaching a maximum at $T_{4}$ in Muletta. As regards such salami therefore we can conclude that a decrease of several volatile compounds occurred in the last ripening period, probably due to the natural loss from the matrix surface.

44 volatile compounds were identified and quantified in Salamini di Mandrogne. As mentioned before, a different behaviour characterizes Salamini di Mandrogne, which are sold just after production. The most abundant compounds were ketones, alcohols, terpenes, sulphur compounds, free fatty acids, and lactones. High concentrations of volatile species formed in carbohydrate fermentation were found, 


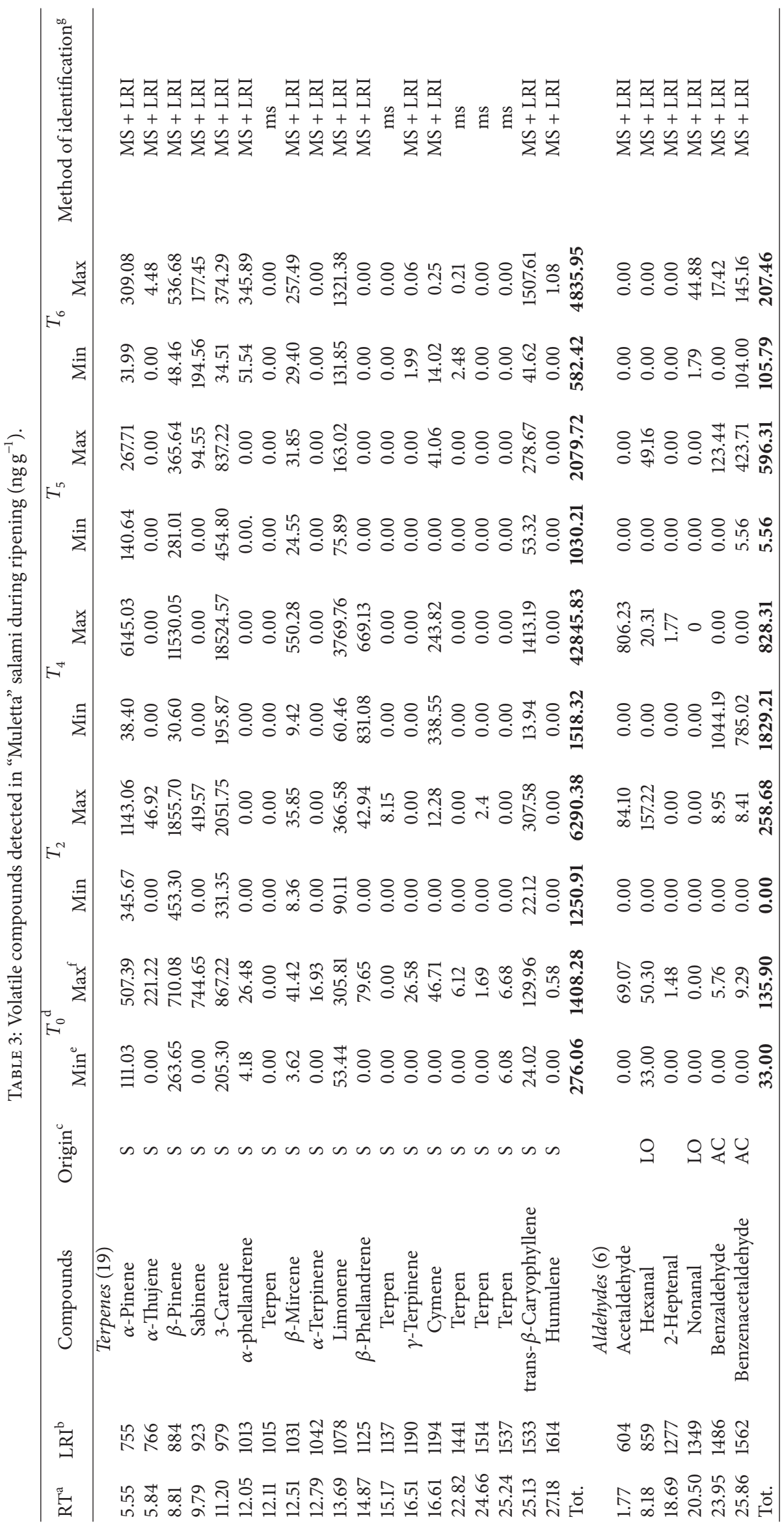




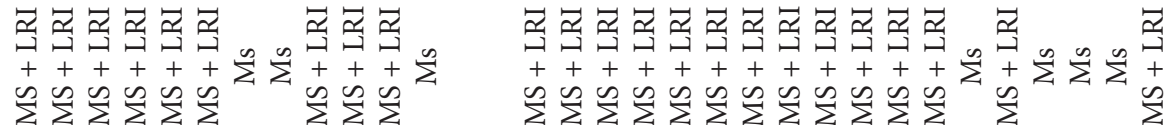
$\mathrm{F}^{\circ}$

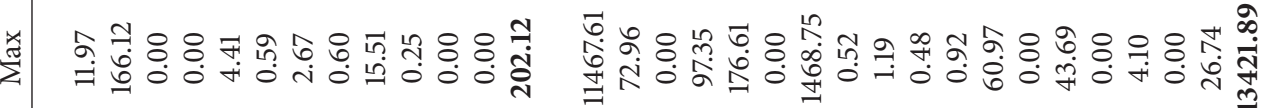

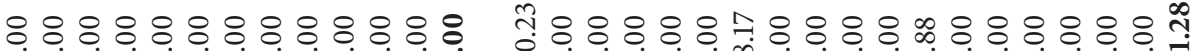

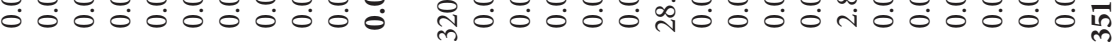

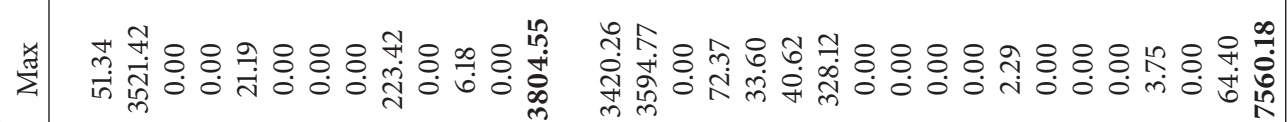
$H^{n}$

声

元 $\mathrm{H}^{+}$

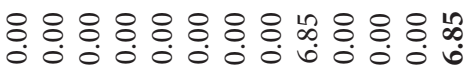

চ্口: \&

宏| बे F

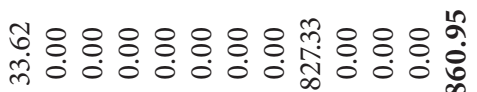

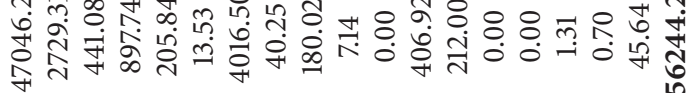

ถ⿻ำ

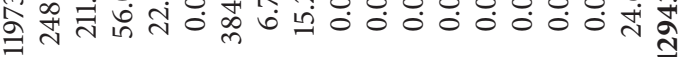

๙ Ұ

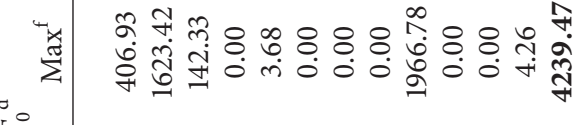

Hi

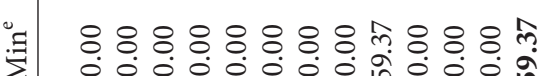

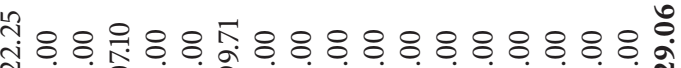

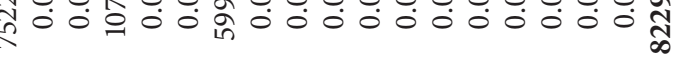

吿

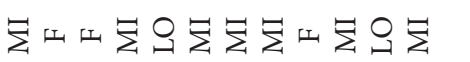

山曲导导

$\stackrel{ }{\Sigma}$
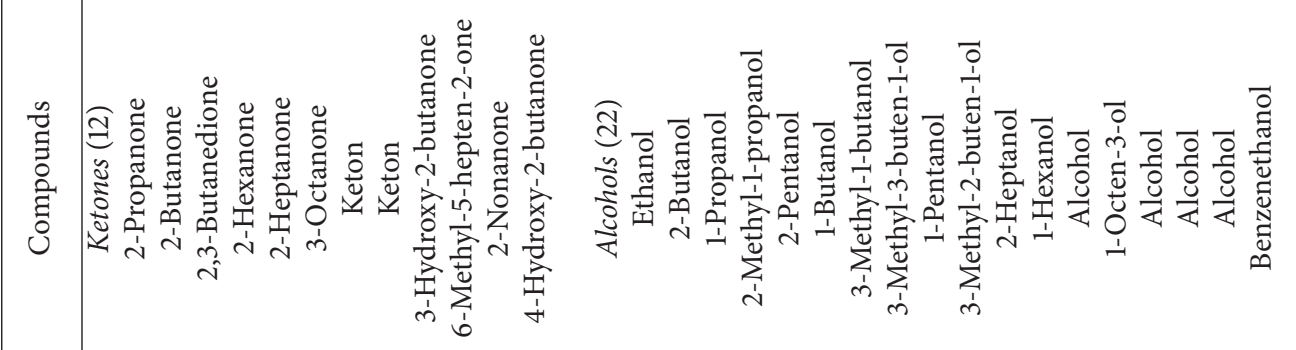

象

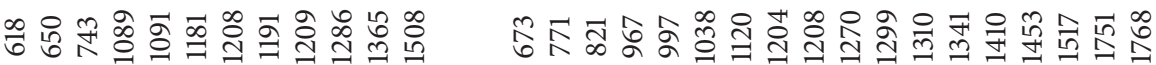

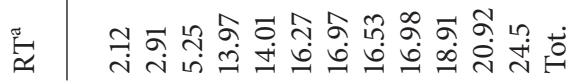

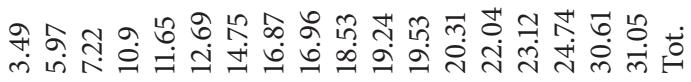




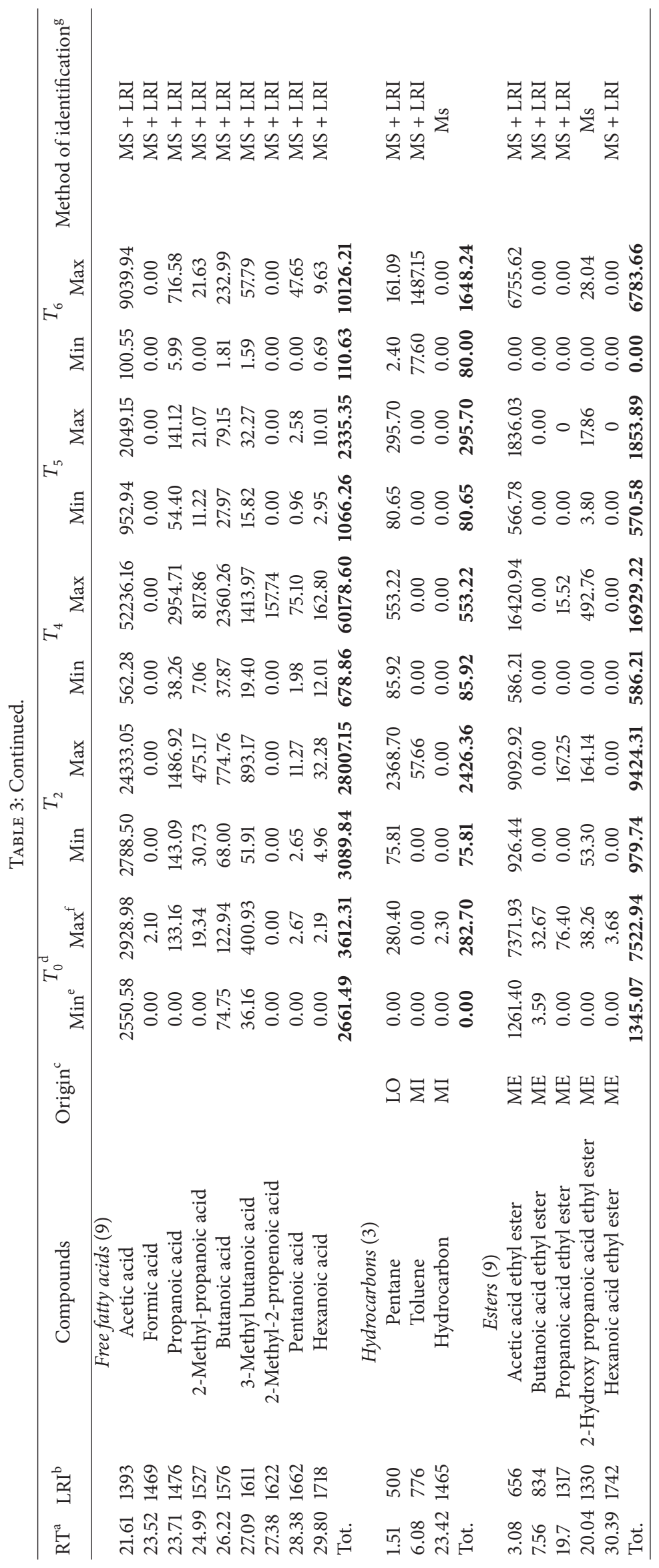




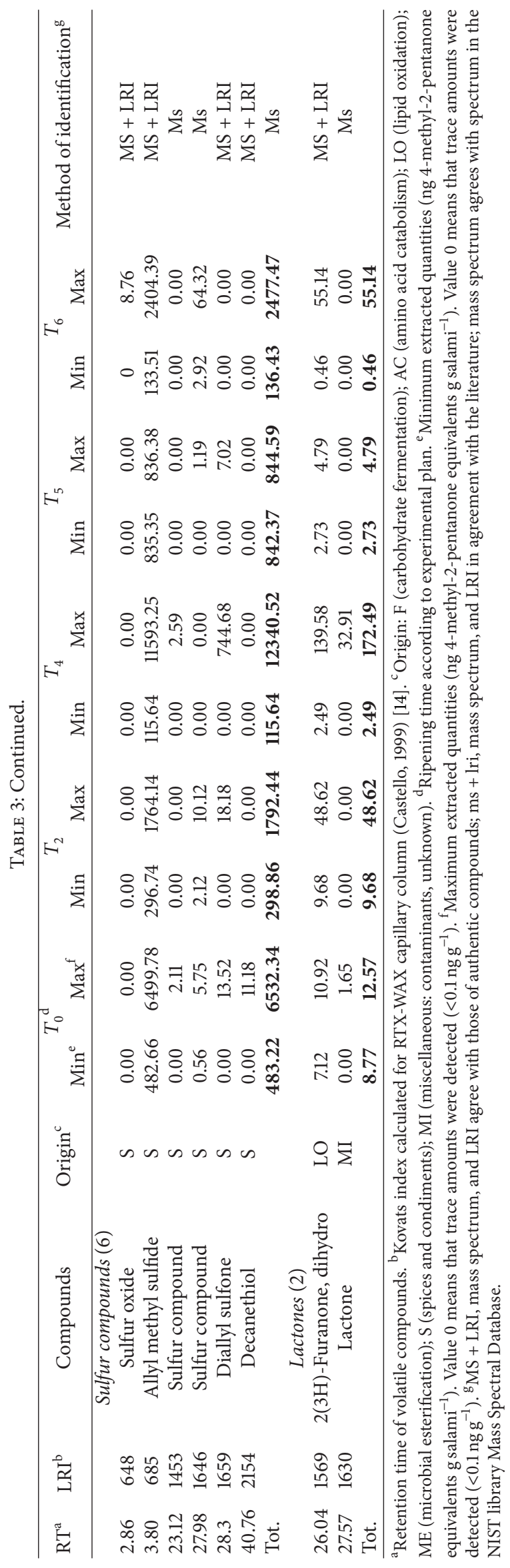




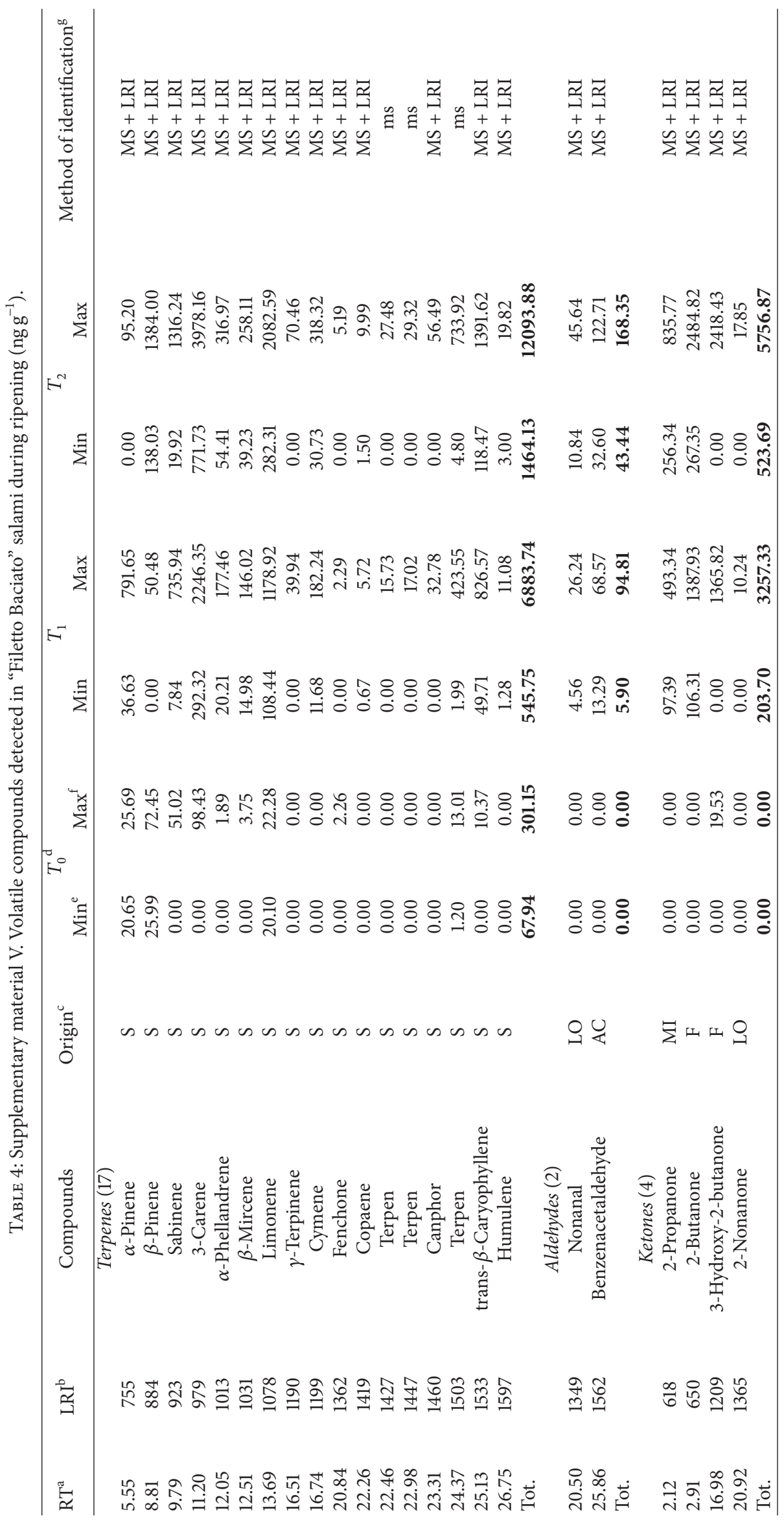




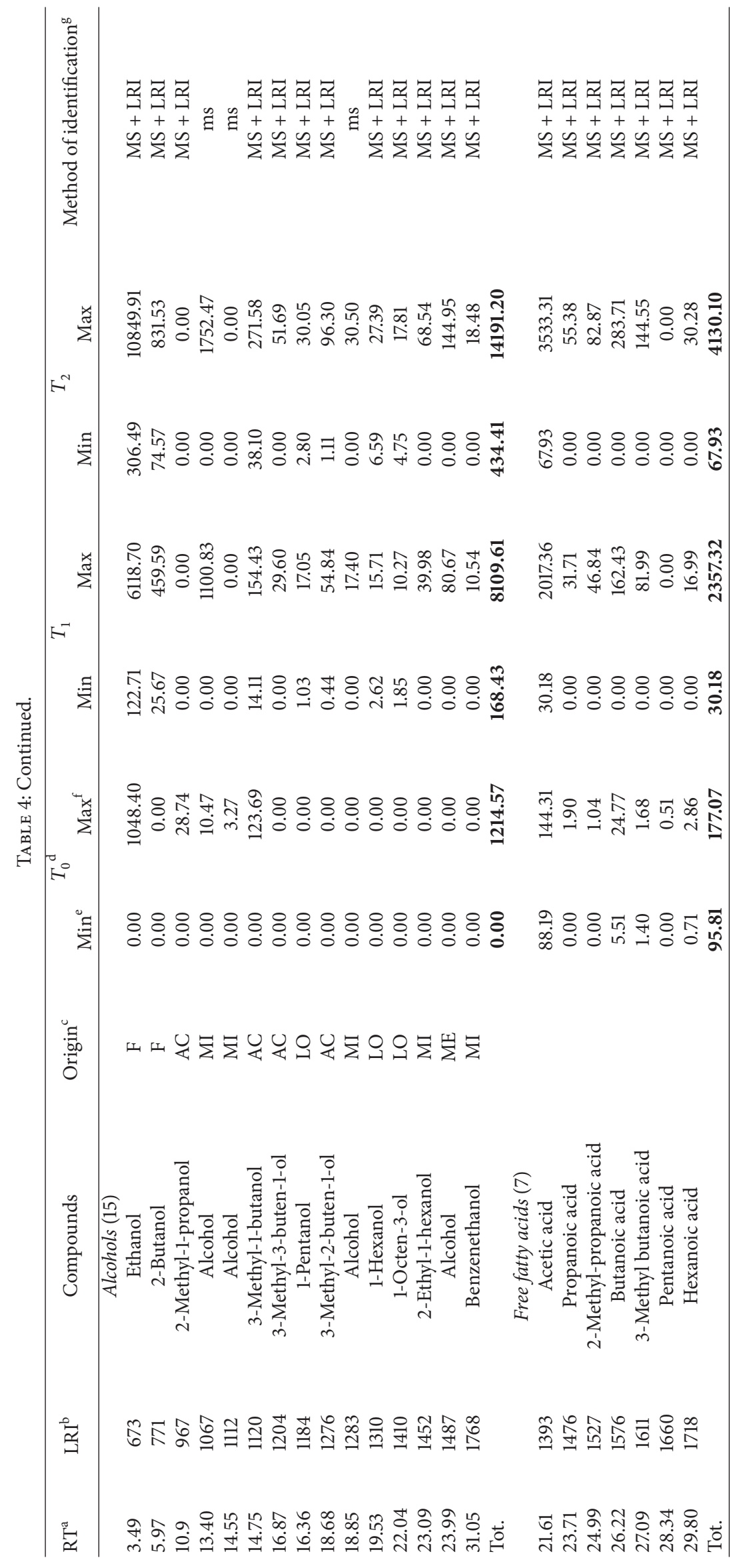




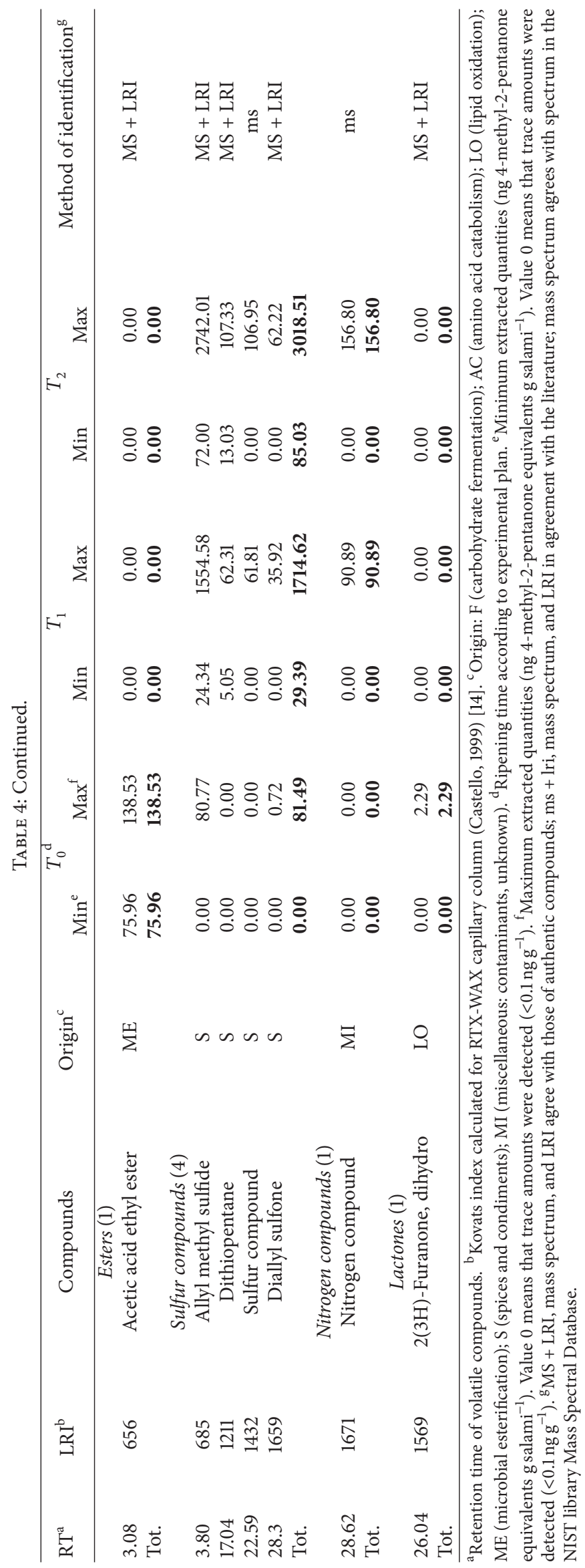




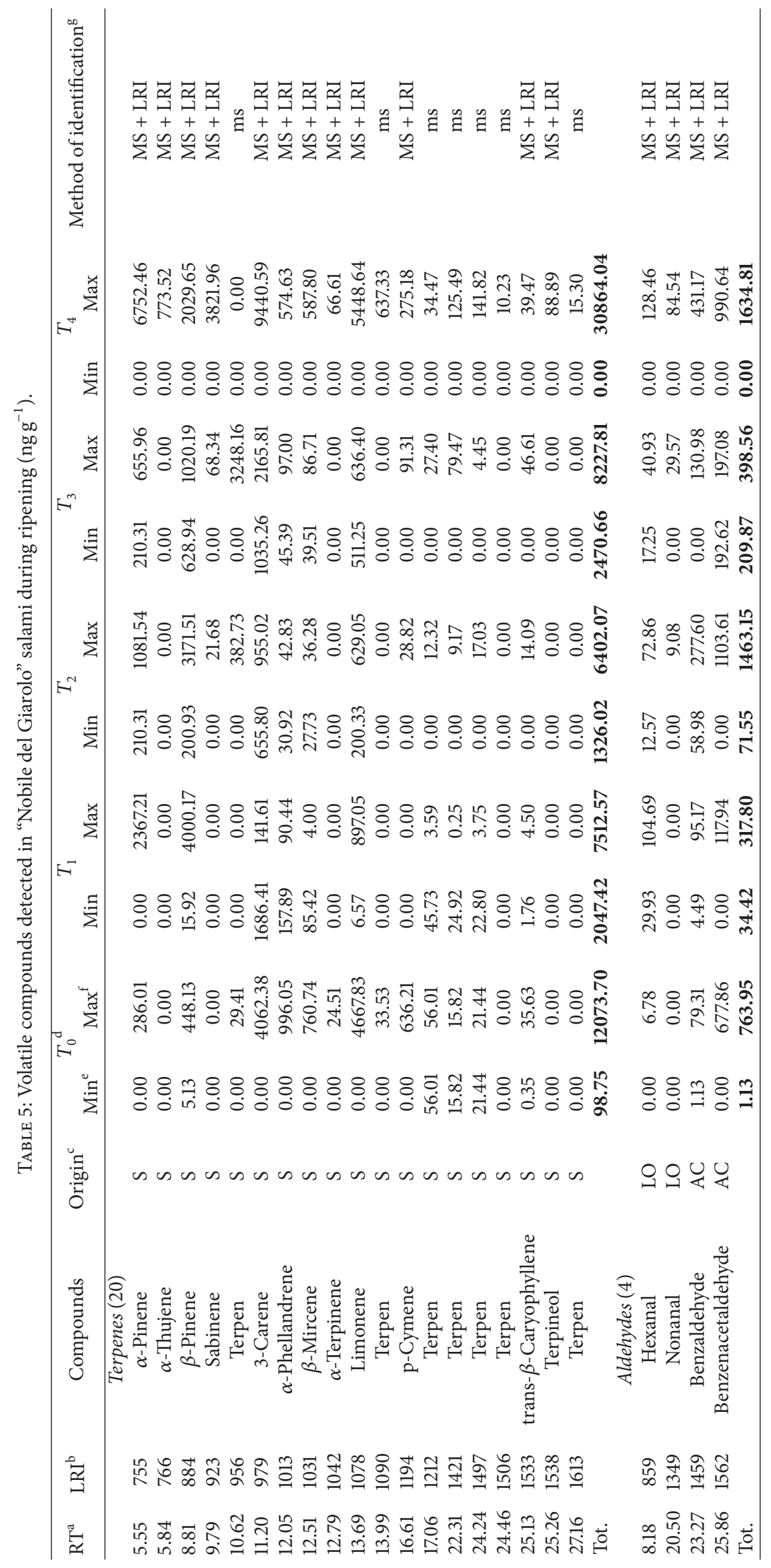




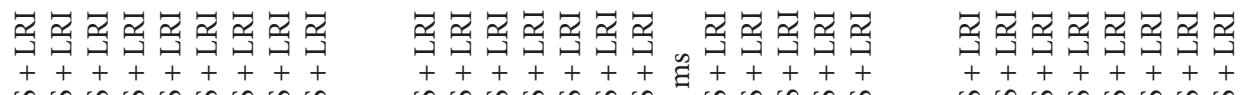

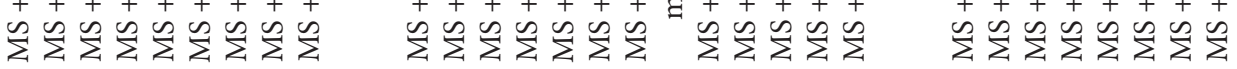

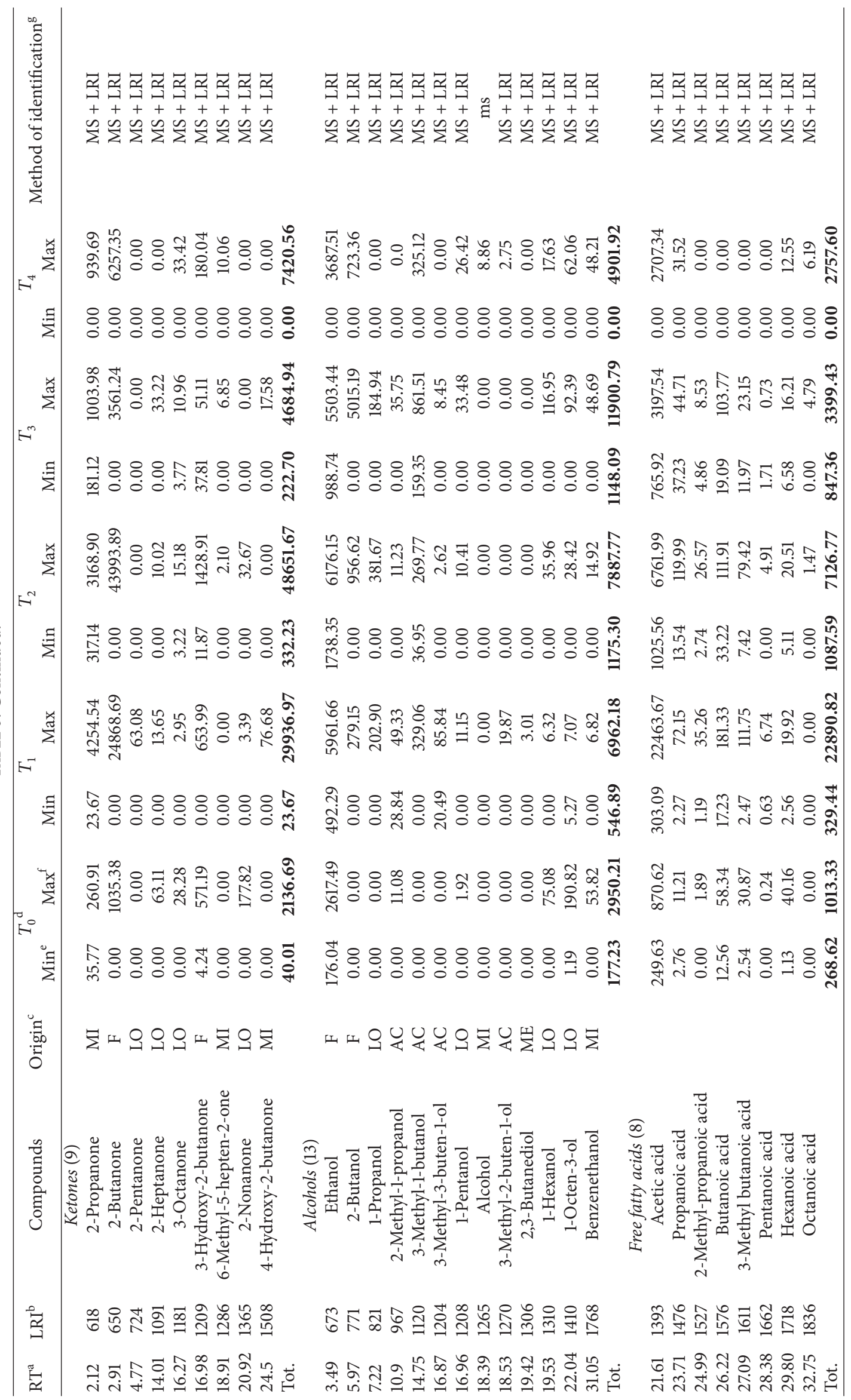




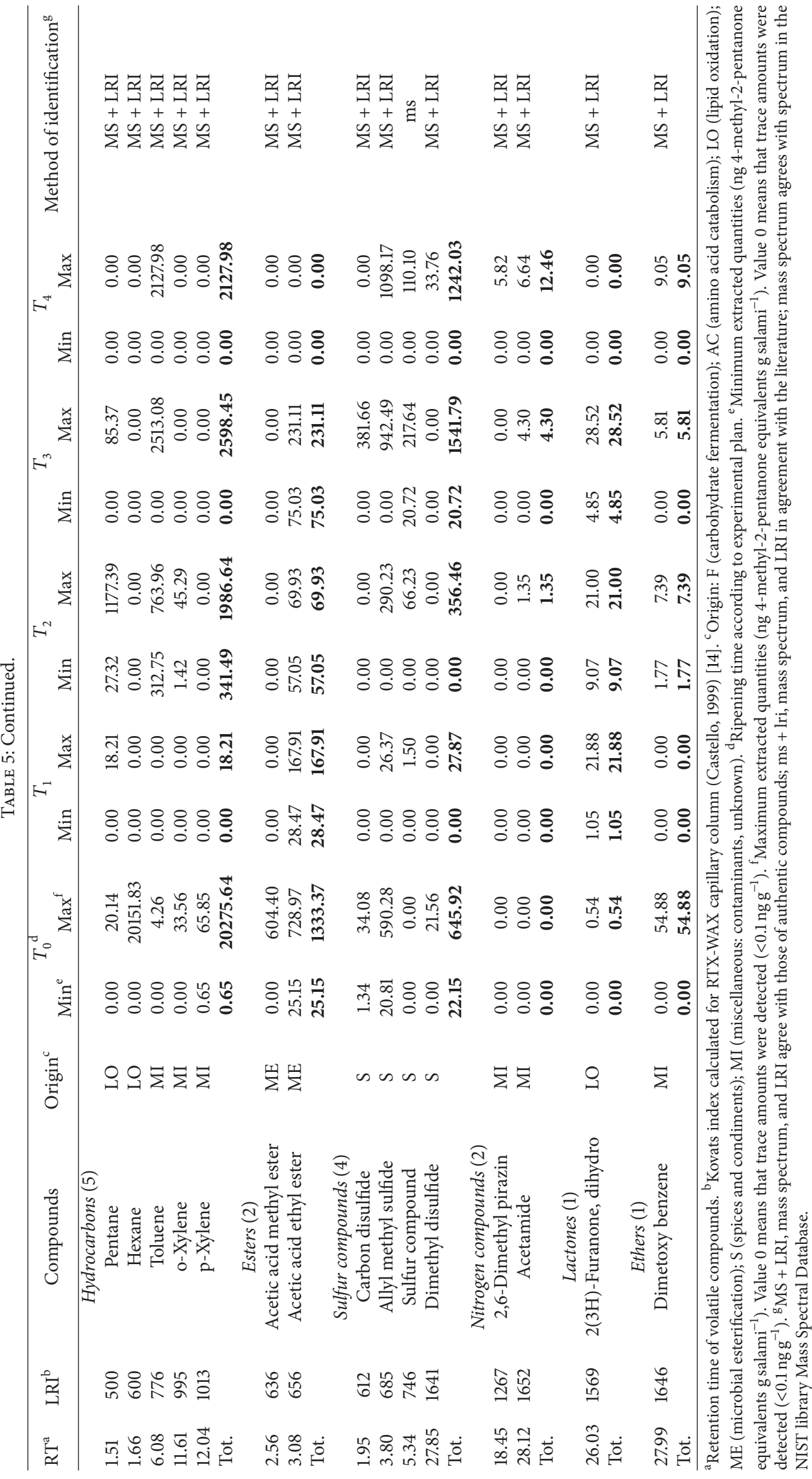


TABLE 6: Volatile compounds detected in "Salamini di Mandrogne" salami (ng g $\left.{ }^{-1}\right)$.

\begin{tabular}{|c|c|c|c|c|c|c|}
\hline \multirow[t]{2}{*}{$\mathrm{RT}^{\mathrm{a}}$} & \multirow{2}{*}{$\mathrm{LRI}^{\mathrm{b}}$} & \multirow{2}{*}{ Compounds } & \multirow{2}{*}{ Origin $^{c}$} & \multicolumn{2}{|c|}{$T_{0}{ }^{\mathrm{d}}$} & \multirow{2}{*}{ Method of identification } \\
\hline & & & & $\operatorname{Min}^{\mathrm{e}}$ & $\operatorname{Max}^{\mathrm{f}}$ & \\
\hline & & Terpenes (14) & & & & \\
\hline 6.14 & 755 & $\alpha$-Pinene & $S$ & 0.00 & 675.10 & MS + LRI \\
\hline 9.75 & 884 & $\beta$-Pinene & S & 31.35 & 1636.87 & $\mathrm{MS}+\mathrm{LRI}$ \\
\hline 12.17 & 979 & 3-Carene & $S$ & 0.00 & 204.03 & MS + LRI \\
\hline 12.98 & 1013 & $\alpha$-Phellandrene & S & 0.00 & 7.32 & MS + LRI \\
\hline 13.45 & 1031 & $\beta$-Myrcene & $S$ & 0.00 & 55.99 & MS + LRI \\
\hline 14.56 & 1078 & Limonene & S & 35.00 & 722.61 & MS + LRI \\
\hline 14.87 & 1125 & Eucalyptol & $S$ & 0.00 & 78.98 & MS + LRI \\
\hline 16.51 & 1190 & $\gamma$-Terpinene & $S$ & 0.00 & 36.01 & MS + LRI \\
\hline 23.73 & 1477 & Canphor & S & 0.00 & 5.45 & MS + LRI \\
\hline 24.74 & 1517 & Linalool & $S$ & 5.92 & 26.52 & MS + LRI \\
\hline 25.70 & 1533 & trans- $\beta$-Caryophyllene & S & 14.58 & 219.65 & MS + LRI \\
\hline 27.17 & 1614 & Humulene & $S$ & 0.00 & 7.98 & MS + LRI \\
\hline 27.70 & 1635 & Terpen & $S$ & 0.00 & 1.16 & MS + LRI \\
\hline 34.20 & 1893 & Eugenol & $S$ & 0.00 & 4.09 & MS + LRI \\
\hline \multirow[t]{2}{*}{ Tot. } & & & & 86.85 & 3681.76 & \\
\hline & & Ketones (3) & & & & \\
\hline 4.92 & 743 & 2,3-Butanedione & $\mathrm{F}$ & 0.00 & 446.48 & MS + LRI \\
\hline 14.04 & 1092 & 2-Octanone & $\mathrm{LO}$ & 0.00 & 1.70 & MS + LRI \\
\hline 17.78 & 1209 & 3-Hydroxy-2-butanone & $\mathrm{F}$ & 579.38 & 52656.86 & MS + LRI \\
\hline \multirow[t]{2}{*}{ Tot. } & & & & 579.38 & 53105.04 & \\
\hline & & Alcohols (11) & & & & \\
\hline 3.85 & 673 & Ethanol & $\mathrm{F}$ & 110.24 & 15032.00 & MS + LRI \\
\hline 10.24 & 967 & 2-Methyl-1-propanol & & 0.00 & 325.00 & MS + LRI \\
\hline 11.54 & 993 & 1-Methoxy-2-propanol & & 0.00 & 39.18 & $\mathrm{MS}+\mathrm{LRI}$ \\
\hline 12.68 & 1038 & 1-Butanol & $\mathrm{F}$ & 0.00 & 35.03 & MS + LRI \\
\hline 13.86 & 1085 & Alcohol & & 0.00 & 2.17 & Ms \\
\hline 15.49 & 1120 & 3-Methyl-1-butanol & $\mathrm{AC}$ & 0.00 & 4116.36 & MS + LRI \\
\hline 16.82 & 1202 & Alcohol & & 0.00 & 2.62 & Ms \\
\hline 17.00 & 1208 & 1-Pentanol & $\mathrm{LO}$ & 0.00 & 140.41 & MS + LRI \\
\hline 20.11 & 1310 & 1-Hexanol & LO & 0.00 & 201.62 & MS + LRI \\
\hline 22.58 & 1431 & 1-Octen-3-ol & LO & 4.63 & 115.49 & MS + LRI \\
\hline \multirow[t]{2}{*}{ Tot. } & & & & 114.87 & 20009.88 & \\
\hline & & Free fatty acids (8) & & & & \\
\hline 22.27 & 1393 & Acetic acid & & 131.03 & 626.36 & MS + LRI \\
\hline 23.53 & 1469 & Formic acid & & 0.00 & 1.20 & MS + LRI \\
\hline 24.31 & 1476 & Propanoic acid & & 0.00 & 14.52 & MS + LRI \\
\hline 25.00 & 1527 & 2-Methyl-propanoic acid & & 0.00 & 12.57 & $\mathrm{MS}+\mathrm{LRI}$ \\
\hline 26.22 & 1576 & Butanoic acid & & 72.00 & 8.86 & MS + LRI \\
\hline 27.08 & 1611 & 3-Methyl-butanoic acid & & 7.12 & 37.29 & MS + LRI \\
\hline 28.39 & 1662 & Pentanoic acid & & 0.00 & 11.77 & MS + LRI \\
\hline 30.38 & 1718 & Hexanoic acid & & 4.00 & 30.96 & MS + LRI \\
\hline \multirow[t]{2}{*}{ Tot. } & & & & 214.15 & 743.53 & \\
\hline & & Sulfur compounds (7) & & & & \\
\hline 4.24 & 685 & Allyl methyl sulfide & S & 0.00 & 947.78 & $\mathrm{MS}+\mathrm{LRI}$ \\
\hline 7.37 & 827 & Mercapto acetone & $S$ & 0.00 & 22.06 & MS + LRI \\
\hline 16.18 & 1177 & Sulfur compound & $S$ & 0.00 & 41.57 & Ms \\
\hline 23.12 & 1453 & Diallyl disulfide & $S$ & 7.78 & 25.93 & MS + LRI \\
\hline 28.30 & 1659 & Sulfur compound & S & 0.00 & 7.04 & Ms \\
\hline 29.43 & 1704 & Sulfur compound & $S$ & 0.00 & 0.60 & Ms \\
\hline Tot. & & & & 7.78 & 1044.98 & \\
\hline
\end{tabular}


TABLE 6: Continued.

\begin{tabular}{|c|c|c|c|c|c|c|}
\hline \multirow{2}{*}{$\mathrm{RT}^{\mathrm{a}}$} & \multirow{2}{*}{$\mathrm{LRI}^{\mathrm{b}}$} & \multirow{2}{*}{ Compounds } & \multirow{2}{*}{ Origin $^{c}$} & \multicolumn{2}{|c|}{$T_{0}{ }^{\mathrm{d}}$} & \multirow{2}{*}{ Method of identification $^{\mathrm{g}}$} \\
\hline & & & & $\operatorname{Min}^{\mathrm{e}}$ & $\operatorname{Max}^{\mathrm{f}}$ & \\
\hline & & Lactones (1) & & & & \\
\hline 26.04 & 1569 & 2(3H)-Furanone, dihydro & LO & 1.61 & 18.29 & MS + LRI \\
\hline Tot. & & & & 1.61 & 18.29 & \\
\hline
\end{tabular}

${ }^{a}$ Retention time of volatile compounds. ${ }^{b}$ Kovats index calculated for RTX-WAX capillary column (Castello, 1999) [14]. ${ }^{c}$ Origin: F (carbohydrate fermentation); AC (amino acid catabolism); LO (lipid oxidation); ME (microbial esterification); S (spices and condiments); MI (miscellaneous: contaminants, unknown). ${ }^{\mathrm{d}}$ Ripening time according to experimental plan. ${ }^{\mathrm{e}}$ Minimum extracted quantities (ng 4-methyl-2-pentanone equivalents g salami ${ }^{-1}$ ). Value 0 means that trace amounts were detected $\left(<0.1 \mathrm{ng} \mathrm{g}^{-1}\right)$. ${ }^{\mathrm{f}}$ Maximum extracted quantities (ng 4-methyl-2-pentanone equivalents $\mathrm{g} \mathrm{salami}^{-1}$ ). Value 0 means that trace amounts were detected $\left(<0.1 \mathrm{ng} \mathrm{g}^{-1}\right) \cdot{ }^{\mathrm{g}} \mathrm{MS}+\mathrm{LRI}$, mass spectrum, and LRI agree with those of authentic compounds; ms + lri, mass spectrum, and LRI in agreement with the literature; mass spectrum agrees with spectrum in the NIST library Mass Spectral Database.

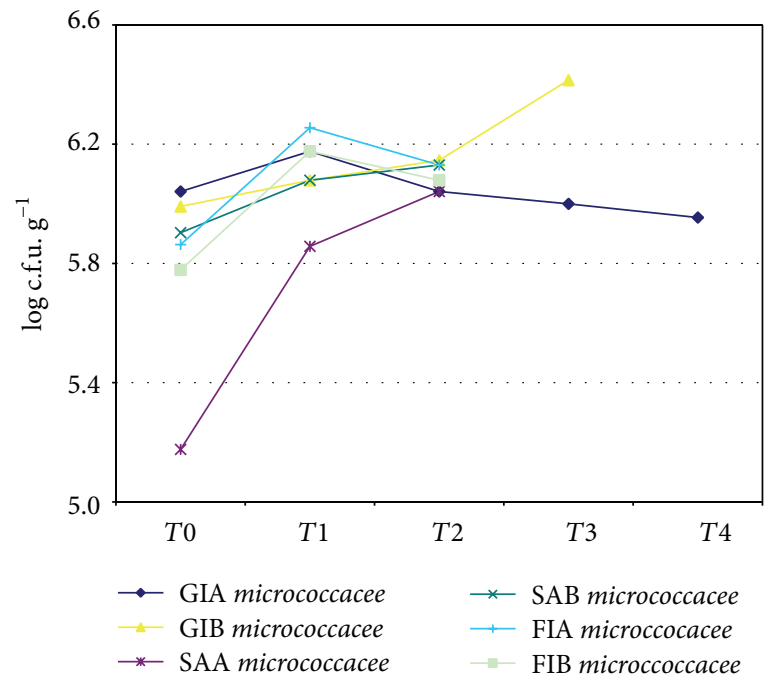

(a)

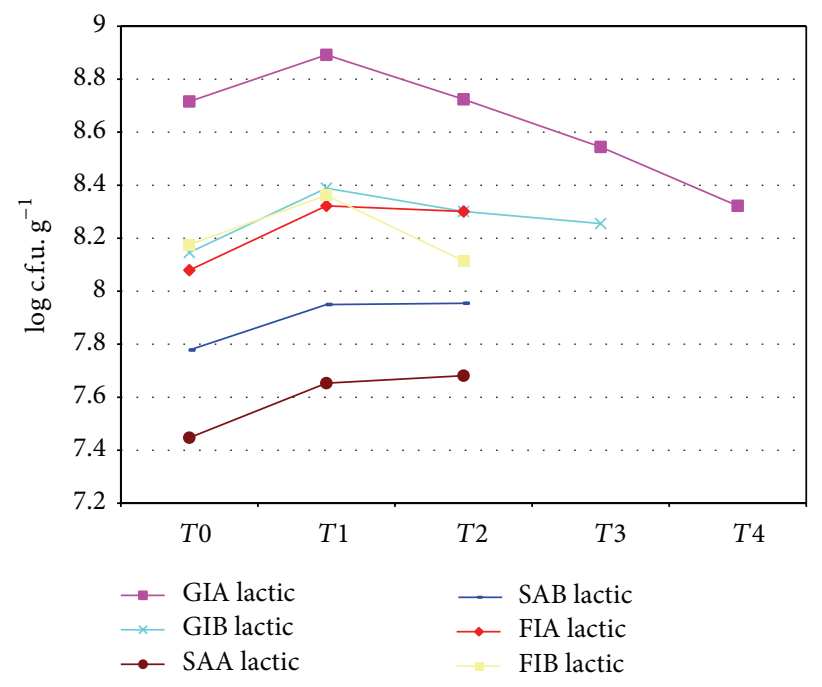

(b)

Figure 2: (a) Evolution of Micrococcaceae bacteria during ripening of Giarolo, Tipico Tortonese, and Filetto Baciato salami (log c.f.u. $\mathrm{g}^{-1}$ ). (b) Evolution of lactic acid bacteria during ripening of Giarolo, Tipico Tortonese, and Filetto Baciato salami (log c.f.u. $\mathrm{g}^{-1}$ ).

especially acetic acid, 2,3-butanedione (diacetyl), and 3hydroxy-2-butanone (acetoin). The result can be related to the high content of Lactobacillus. 3-Methyl-1-butanol (likely formed by reduction of the corresponding aldehydes) and ethanol were the most abundant alcohols found in Salamini di Mandrogne. Some sulfur-containing compounds were also identified, the most abundant being allyl methyl sulphide, while the most abundant terpenes were $\delta$-3-carene and $\beta$ caryophyllene, which probably derive from black pepper, cloves, and nutmeg used in the preparation [32-36].

3.4. Multivariate Analysis. Data were arranged in a $42 \times 240$ matrix ( 42 being the samples at different ripening times and 240 the variables). All variables expressed as concentrations and percentages were corrected for the amount of water present in each sample.

PCA on the Overall Dataset. PCA was performed on the overall dataset $(42 \times 248)$ after autoscaling and elimination of sample MUA4, resulting to be an outlier from a first analysis. The first two PCs explain about $22 \%$ of the overall variance, indicating a low correlated and redundant data structure.
Figure 3(a) represents the score plot of the first two PCs; three main groups of samples can be identified:

group 1: constituted by almost all samples belonging to Muletta type;

group 2: constituted by almost all samples belonging to Salamini di Mandrogne type;

group 3: constituted by almost all other samples.

The samples appear separated according to the type of product. The two most different groups are those characterised by the most different maximum ripening times: Salamini di Mandrogne (sold fresh, group 2) and Muletta (six-month ripening, group 1). Moreover, Salamini di Mandrogne are produced with veal meat and are well separated from those produced with pork meat.

No trend as a function of ripening time can be observed.

PCA at the Selling Stage. A further PCA was then performed on the data collected at the selling stage, with the aim to further investigate the differences between the samples at the time when they are consumed. PCA was performed, after 


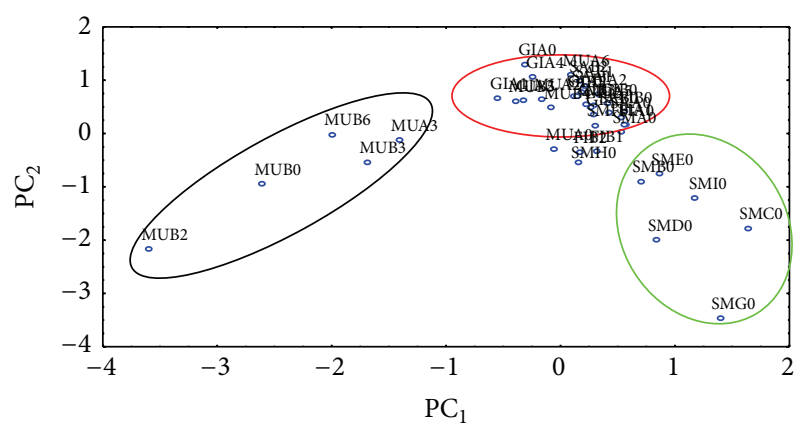

(a)

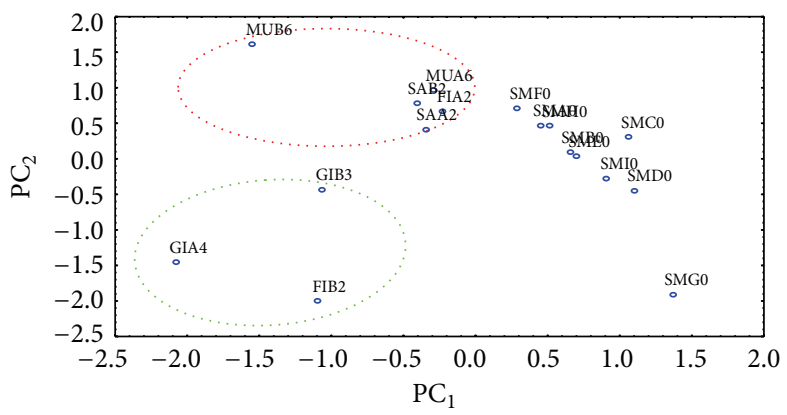

(b)

Figure 3: (a) Results of PCA applied to the overall dataset after autoscaling: score plot of $\mathrm{PC}_{1}$ versus $\mathrm{PC}_{2}$; (b) results of PCA applied to the samples analysed at the selling time after autoscaling: score plot of $\mathrm{PC}_{1}$ versus $\mathrm{PC}_{2}$.

autoscaling, on the $17 \times 214$ matrix that contains all products, including Salamini di Mandrogne. Some variables showing a null variance for this subset of samples were eliminated from the dataset. The first two PCs (29\% total variance) were considered significant and again indicate a low correlated data structure.

In the corresponding score plot (Figure 3(b)), Salamini di Mandrogne are grouped at positive scores along $\mathrm{PC}_{1}$, while the other samples lay at negative values. $\mathrm{PC}_{1}$ seems mostly related to the ripening period that the samples undergo until selling, since the fresh products are at positive scores, while the most ripened ones are located at large negative scores along the first PC. This last group can be further divided in two groups according to the positive or negative score on $\mathrm{PC}_{2} \cdot \mathrm{PC}_{2}$ is therefore able to separate Nobile del Giarolo (negative scores on $\mathrm{PC}_{2}$ ) from the other samples that came all from a zone of the Alessandria province around Tortona (positive scores on the same PC). The analysis of the corresponding loadings allowed the identification of the main differences between the groups identified. Salamini di Mandrogne are characterised, as expected, by large values of moisture. Moreover, they are characterised by a small aroma of pepper ( $\alpha$-phellandrene, $\delta$ limonene, $\alpha$-pinene, and $\beta$-myrcene) and garlic (diallyl disulphide), a low content of spices (3-carene, sabinene), small amounts of biogenic amines, and a low oxidation of unsaturated fatty acids (hexanal). The other samples are characterised by an opposite behaviour, showing a larger contribution of variables related to aroma. These samples, however, are separated in two groups along $\mathrm{PC}_{2}$ : Nobile del Giarolo is characterised by a larger amount of spices ( $\beta$-myrcene, $\mathrm{p}$-cymene) and pepper ( $\alpha$-pinene, $\alpha$-phellandrene, sabinene) and a higher carbohydrate fermentation (2 butanol, 2-butanone) [7, 12]. The samples from the Tortona area instead (positive scores on $\mathrm{PC}_{2}$ ) are characterised by a larger content of fats and tyramine. The analysis therefore points out the existence of three main groups of samples: their differences are mainly related to the ripening period they undergo (accounted for by $\mathrm{PC}_{1}$ ) and to the ingredients used (different aromas and starting meat mixture). A further Cluster Analysis was applied on this dataset: Figure 4 represents the dendrogram obtained by the Ward method (Euclidean distances) applied

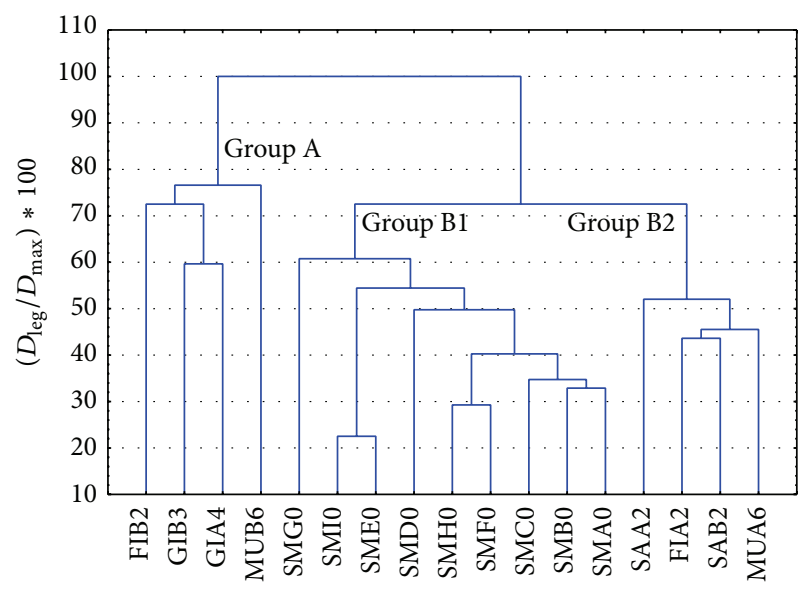

FIGURE 4: Dendrogram calculated by the Ward method with Euclidean distances on the dataset constituted by all the samples characterised at the selling time, after autoscaling. Samples are reported on the $x$-axis while distance between samples/groups is reported as percentage on the $y$-axis.

to the dataset after autoscaling. The dendrogram reports the samples on the $x$-axis; two main groups can be detected: the first one (group A) consists of the samples showing the largest negative scores along $\mathrm{PC}_{1}$. The other group can be divided in two subgroups (groups B1 and B2): group B1 contains all Salamini di Mandrogne samples that showed the largest positive scores on $\mathrm{PC}_{1}$; group $\mathrm{B} 2$ instead is constituted by the other samples, showing intermediate scores along the first PC. Cluster Analysis therefore confirms the results obtained by PCA, showing that the most important information regards changes in the chemical composition that can be ascribed to ripening.

\section{Conclusions}

This study is focused on the characterisation of typical salami products of the Alessandria province territory (North West of Italy). Seventeen small or medium salami producers from this area were involved in the study and provided six types of typical salami. Samples were characterised for what regards 
the aroma component and nutritional feature with a double aim: obtaining a screening of the characteristics of different products and following their evolution along with ripening.

The overall results obtained point out that the products investigated do not deviate from analogous European products. The attention was then focussed on the production and selling times to provide a characterisation of the samples at the moment when they are prepared and finally sold. The analysis was carried out with the help of multivariate statistical tools, as Principal Component Analysis and Cluster Analysis. The results show the existence of three main groups of samples: Salamini di Mandrogne, Muletta, and Nobile del Giarolo. Among them, Salamini di Mandrogne certainly appear as quite different products since they are sold fresh and present a particular recipe constituted mainly from veal meat: these features is reflected in a low content of biogenic amines, a low carbohydrate fermentation, and a low content of aroma components related to spices. The other two products are commercialised after a ripening period of four months for Nobile del Giarolo and of six months for Muletta. These two products can be differentiated mainly regarding carbohydrate fermentation and aroma component related to spices (larger in Nobile del Giarolo) and fats and content of tyramine (larger in Muletta). Some considerations can also be drawn with respect to the nutritional characterization of the samples observing BA content, as their profile can be related to a good or bad ripening working out, according to which BA is predominant. Tyramine is usually the dominant amine in salami and is considered an index of correct ripening working out: in the investigated samples, its values are in agreement with other traditional Italian [34] and European fermented sausages [1], even if it is not always the dominant amine: for many samples histamine is the most abundant one with concentration ranges larger than the law limit $\left(100 \mathrm{mg} \mathrm{Kg}^{-1}\right)$. In conclusion results obtained by this study confirm that the determination of various typologies of parameters (volatile compounds, amino acids, chemical and microbiological parameters, and biogenic amine) may be important to assess the quality of raw and final products in terms of optimal condition of production and preservation of typical meat products during their shelf-life. The entire approach could provide a basis for a possible PDO or PGI label assignment.

\section{Conflict of Interests}

The authors declare that they have no conflict of interests.

\section{Acknowledgments}

The authors gratefully acknowledge the financial support by Fondazione Cassa di Risparmio di Alessandria (Italy) and the cooperation and the assistance of the veterinaries of the ASL AL (Alessandria, Italy).

\section{References}

[1] M. L. Latorre-Moratalla, T. Veciana-Nogués, S. Bover-Cid et al., "Biogenic amines in traditional fermented sausages produced in selected European countries," Food Chemistry, vol. 107, no. 2, pp. 912-921, 2008.

[2] M. Sidira, M. Kanellaki, and Y. Kourkoutas, "Profile of aroma-related volatile compounds isolated from probiotic dryfermented sausages produced with free or immobilized L. Casei using SPME GC/MS analysis," in Nutrition, Functional and Sensory Properties of Foods, 2013.

[3] R. M. L. de Campos, E. Hierro, J. A. Ordóñez, and L. de la Hoz, "Fatty acid and volatile compound composition of Italian and Brazilian Milano salami," Sciences des Aliments, vol. 27, no. 3, pp. 234-244, 2007.

[4] M. Flores and D. Hernández, "Optimization of multiple headspace solid-phase microextraction for the quantification of volatile compounds in dry fermented sausages," Journal of Agricultural and Food Chemistry, vol. 55, no. 21, pp. 8688-8695, 2007.

[5] A. Marco, J. L. Navarro, and M. Flores, "Quantitation of selected odor-active constituents in dry fermented sausages prepared with different curing salts," Journal of Agricultural and Food Chemistry, vol. 55, no. 8, pp. 3058-3065, 2007.

[6] A. Meynier, E. Novelli, R. Chizzolini, E. Zanardi, and G. Gandemer, "Volatile compounds of commercial Milano salami," Meat Science, vol. 51, no. 2, pp. 175-183, 1999.

[7] L. O. Sunesen, V. Dorigoni, E. Zanardi, and L. Stahnke, "Volatile compounds released during ripening in Italian dried sausage," Meat Science, vol. 58, no. 1, pp. 93-97, 2001.

[8] R. di Cagno, C. Chaves Lòpez, R. Tofalo et al., "Comparison of the compositional, microbiological, biochemical and volatile profile characteristics of three Italian PDO fermented sausages," Meat Science, vol. 79, no. 2, pp. 224-235, 2008.

[9] F. Bianchi, C. Cantoni, M. Careri, L. Chiesa, M. Musci, and A. Pinna, "Characterization of the aromatic profile for the authentication and differentiation of typical Italian dry-sausages," Talanta, vol. 72, no. 4, pp. 1552-1563, 2007.

[10] M. T. Osorio, J. M. Zumalacárregui, A. Figueira, and J. Mateo, "Fatty acid composition in subcutaneous, intermuscular and intramuscular fat deposits of suckling lamb meat: effect of milk source," Small Ruminant Research, vol. 73, no. 1-3, pp. 127-134, 2007.

[11] M. P. Rodríguez, J. Carballo, and M. López, “Characterization of the lipid fraction of some Galician (NW of Spain) traditional meat products," Grasas y Aceites, vol. 52, no. 5, pp. 291-296, 2001.

[12] B. M. Franke, G. Gremaud, R. Hadorn, and M. Kreuzer, "Geographic origin of meat-elements of an analytical approach to its authentication," European Food Research and Technology, vol. 221, no. 3-4, pp. 493-503, 2005.

[13] S. Kelly, K. Heaton, and J. Hoogewerff, “Tracing the geographical origin of food: the application of multi-element and multiisotope analysis," Trends in Food Science and Technology, vol. 16, no. 12 , pp. 555-567, 2005.

[14] G. Castello, "Retention index systems: alternatives to the nalkanes as calibration standards," Journal of Chromatography A, vol. 842, no. 1-2, pp. 51-64, 1999.

[15] AOAC, Official Methods of Analysis: 950.46, Association of Analytical Chemist, Washington, DC, USA, 1990.

[16] AOAC, Official Methods of Analysis: 920.158, Association of Analytical Chemist, Washington, DC, USA, 1995.

[17] AOCS, Official Methods and Recommended Practices, American Oil Chemists' Society, Champaign, Ill, USA, 5th edition, 1997.

[18] P. T. Slack, Analytical Methods Manual, Leatherhead Food R.A., London, UK, 1987. 
[19] L. M. Chiesa, S. Soncin, P. A. Biondi, P. Cattaneo, and C. Cantoni, "Different fibres for the analysis of volatile compounds in processed meat products by solid phase micro-extraction (SPME)," Veterinary Research Communications, vol. 30, no. 1, pp. 349-351, 2006.

[20] B. Herranz, J. A. Ordóñez, L. de la Hoz, E. Hierro, E. Soto, and M. I. Cambero, "Fatty acid composition of salami from different countries and their nutritional implications," International Journal of Food Sciences and Nutrition, vol. 59, no. 7-8, pp. 607-618, 2008.

[21] M. H. S. Santos, "Biogenic amines: their importance in foods," International Journal of Food Microbiology, vol. 29, no. 2-3, pp. 213-231, 1996.

[22] T. Hernández-Jover, M. Izquierdo-Pulido, M. T. VecianaNogués, and M. C. Vidal-Carou, "Ion pair high-performance liquid chromatographic determination of biogenic amines in meat and meat products," Journal of Agricultural and Food Chemistry, vol. 44, no. 9, pp. 2710-2715, 1996.

[23] S. Soncin, L. M. Chiesa, C. Cantoni, and P. A. Biondi, "Preliminary study of the volatile fraction in the raw meat of pork, duck and goose," Journal of Food Composition and Analysis, vol. 20, no. 5, pp. 436-439, 2007.

[24] L. M. Chiesa, S. Panseri, S. Soncin, L. Vallone, and I. Dragoni, "Determination of styrene content in Gorgonzola PDO cheese by headspace solid phase micro-extraction (HS-SPME) and gas-chromatography mass-spectrometry (GC-MS)," Veterinary Research Communication, vol. 34, supplement 1, pp. S167-S170, 2010.

[25] V. M. Moretti, G. Madonia, C. Diaferia et al., "Chemical and microbiological parameters and sensory attributes of a typical Sicilian salami ripened in different conditions," Meat Science, vol. 66, no. 4, pp. 845-854, 2004.

[26] L. H. Stahnke, "Aroma components from dried sausages fermented with Staphylococcus xylosus," Meat Science, vol. 38, no. 1, pp. 39-53, 1994.

[27] M. Wettasinghe, T. Vasanthan, F. Temelli, and K. Swallow, "Volatile flavour composition of cooked by-product blends of chicken, beef and pork: a quantitative GC-MS investigation," Food Research International, vol. 34, no. 2-3, pp. 149-158, 2001.

[28] M. Careri, A. Mangia, G. Barbieri, L. Bolzoni, R. Virgili, and G. Parolari, "Sensory property relationships to chemical data of Italian- type dry-cured ham," Journal of Food Science, vol. 58, no. 5, pp. 968-972, 1993.

[29] R. A. Edwards, J. A. Ordóñez, R. H. Dainty, E. M. Hierro, and L. de la Hoz, "Characterization of the headspace volatile compounds of selected Spanish dry fermented sausages," Food Chemistry, vol. 64, no. 4, pp. 461-465, 1999.

[30] F. Shahidi and R. B. Pegg, "Hexanal as an indicator of meat flavor deterioration," Journal of Food Lipids, vol. 1, no. 3, pp. 177-186, 1994.

[31] G. Procida, L. S. Conte, S. Fiorasi, G. Comi, and L. G. Favretto, "Study on volatile components in salami by reverse carrier gas headspace gas chromatography-mass spectrometry," Journal of Chromatography A, vol. 830, no. 1, pp. 175-182, 1999.

[32] S. Dellaglio, E. Casiraghi, and C. Pompei, "Chemical, physical and sensory attributes for the characterization of an Italian drycured sausage," Meat Science, vol. 42, no. 1, pp. 25-35, 1996.

[33] R. M. L. de Campos, E. Hierro, J. A. Ordóñez, T. M. Bertol, N. N. Terra, and L. de la Hoz, "Fatty acid and volatile compounds from salami manufactured with yerba mate (Ilex paraguariensis) extract and pork back fat and meat from pigs fed on diets with partial replacement of maize with rice bran," Food Chemistry, vol. 103, no. 4, pp. 1159-1167, 2007.

[34] J. D. Coïsson, C. Cerutti, F. Travaglia, and M. Arlorio, "Production of biogenic amines in 'Salamini italiani alla cacciatora PDO,' Meat Science, vol. 67, no. 2, pp. 343-349, 2004.

[35] E. Casiraghi, C. Pompei, S. Dellaglio, G. Parolari, and R. Virgili, "Quality attributes of Milano salami, an Italian drycured sausage," Journal of Agricultural and Food Chemistry, vol. 44, no. 5, pp. 1248-1252, 1996.

[36] E. Alissandrakis, P. A. Tarantilis, P. C. Harizanis, and M. Polissiou, "Evaluation of four isolation techniques for honey aroma compounds," Journal of the Science of Food and Agriculture, vol. 85, no. 1, pp. 91-97, 2005. 

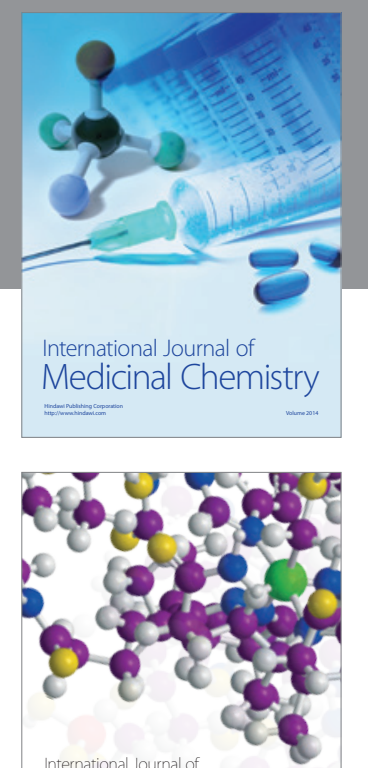

\section{Carbohydrate} Chemistry

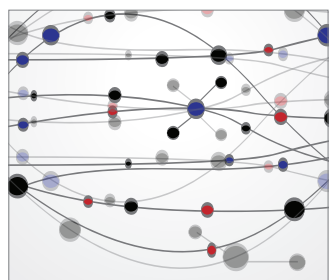

The Scientific World Journal
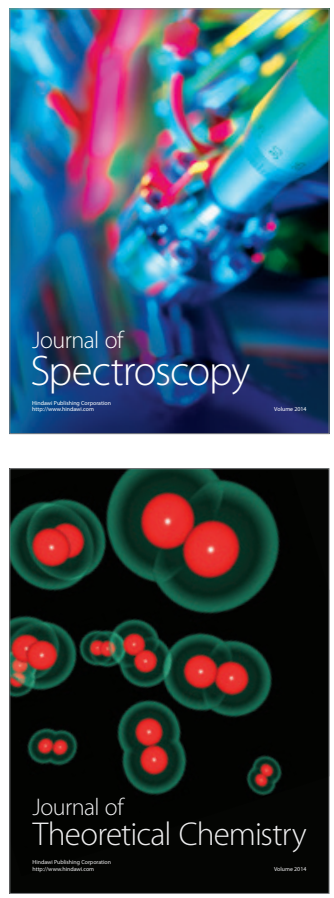
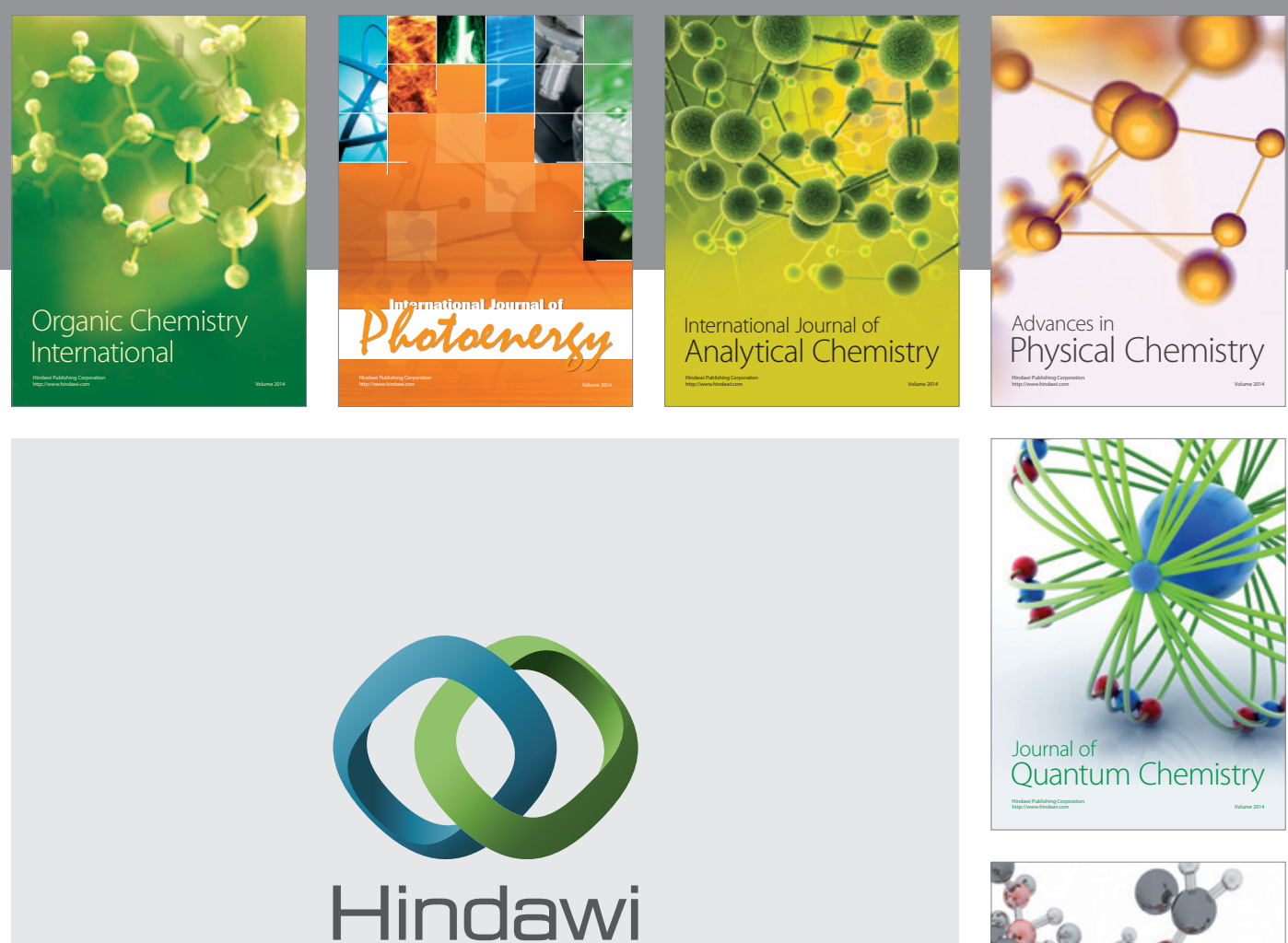

Submit your manuscripts at

http://www.hindawi.com

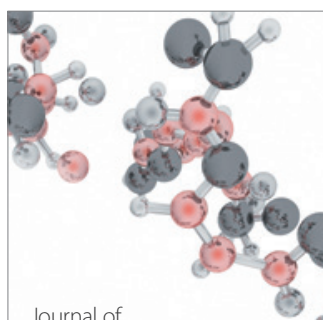

Analytical Methods

in Chemistry

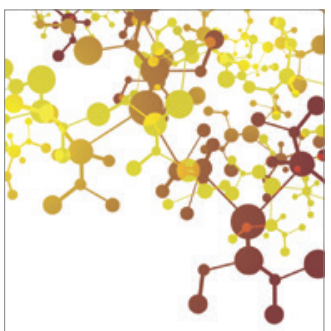

Journal of

Applied Chemistry

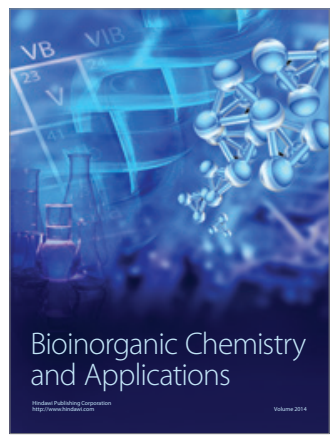

Inorganic Chemistry
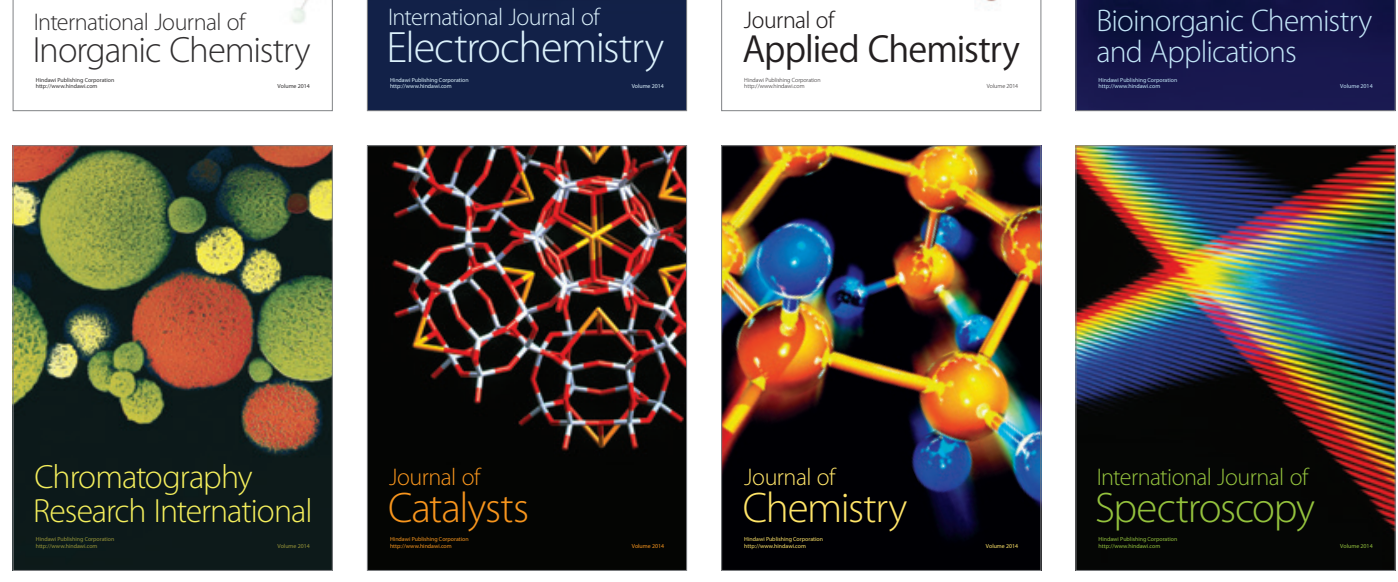